\title{
Pandemic-related financial market volatility spillovers: Evidence from the Chinese COVID-19 epicentre
}

\author{
Shaen Corbet ${ }^{a, b *}$, Yang (Greg) $\mathrm{Hou}^{a}$, Yang Hu${ }^{a}$, Les Oxley ${ }^{a}$, Danyang $\mathrm{Xu}^{a}$ \\ ${ }^{a}$ School of Accounting, Finance and Economics, University of Waikato, New Zealand \\ ${ }^{b}$ DCU Business School, Dublin City University, Dublin 9, Ireland \\ * Corresponding Author: shaen.corbet@dcu.ie
}

\begin{abstract}
Utilising Chinese-developed data based on long-standing influenza indices, and the more recentlydeveloped coronavirus and face mask indices, we set out to test for the presence of volatility spillovers from Chinese financial markets upon a broad number of traditional financial assets during the outbreak of the COVID-19 pandemic. Such indices are used to specifically measure the performance of Chinese companies who are inherently involved in the R\&D and production of materials and products used to mitigate and counteract the effects of influenza and coronavirus, therefore, such indices present a unique barometer of broad population-based sentiment relating to COVID-19 in comparison to traditional Chinese influenza. Within days of the formal announcement of the COVID-19 outbreak, results indicate exceptionally pronounced and persistent impacts of the coronavirus pandemic upon Chinese financial markets, compared to that of the traditional and longstanding influenza index. Further, in a novel finding to date, COVID-19 is found to have had a substantial effect on directional spillovers upon the Bitcoin market. Cryptocurrency-based confidence appears to have been instigated through government-developed education schemes, which are identified as one possible explanation for our results, which are found to remain robust across both data-frequency and methodological variation.
\end{abstract}

Keywords: COVID-19; Coronavirus; China; Volatility Spillovers; Bitcoin; Flight-to-Safety. 


\section{Introduction}

The COVID-19 pandemic that developed in Wuhan, China in late-2019, has presented a stark warning to international financial markets with regards to the exceptional vulnerabilities and fragility that can quickly transpire and disseminate. The first reported case of an individual suffering from COVID-19 can be traced back to 17 November 2019 according to media reports sourced in unpublished Chinese government data. However, the first official identification by international organisations such as the World Heath Organisation (WHO), was on the 31 December 2019. Since these two dates, we have observed a worldwide economic slowdown that has thrust a number of countries into severe recessions, with the probability of a broad economic depression ever increasing. The pandemic does, however, present a unique opportunity to specifically investigate two key questions: 1) how do volatility spillovers and episodes of financial market contagion behave during pandemics; and 2) how did Chinese coronavirus/influenza indices behave with regards to total and directional pairwise volatility spillovers.

While investigating the traditional interactions between the Chinese coronavirus and influenza indices, and a number of traditional financial markets during the current pandemic, we specifically test how volatility interactions differed in the aftermath of the coronavirus outbreak. As further developed by Gamba-Santamaria et al. [2017] and Antonakakis et al. [2019], we build on the framework of Diebold and Yilmaz [2012] and construct volatility spillover indices using a DCC-GARCH t-Copula framework to model the multivariate relationships of volatility among stock, commodity (agriculture, energy and precious metal), foreign exchange and cryptocurrency markets. It is important to understand whether the Chinese influenza indices acted as a true financial barometer based on the depth and scale of the Chinese coronavirus outbreak. Such research is of significant importance should population centres face repeated closures and lock-downs during future attempts to reduce the reproduction rates of COVID-19 and any other pandemics that we might face in the future.

Financial crises are found to present a number of notable similarities during their development and expansion across traditional financial assets (Reinhart and Rogoff [2008], Diebold and Yilmaz [2012]), most notably through the presence of substantial and significant volatility spillovers. Diebold and Yilmaz [2012] considered whether the identification of such spillovers could provide evidence of an 'early warning system' for emergent crises. Within this context, and considering the severity of the COVID-19 pandemic, such early identification of market stresses, as measured 
through an abnormal influenza dynamic in Chinese markets, could have provided substantial and timely warnings about the forthcoming severity of the current worldwide pandemic. Methodological support could have been provided through the use of a volatility spillover measure that is based specifically on forecast error variance decompositions from vector autoregressions. The framework of Diebold and Yilmaz [2012] in particular allows us to use directional volatility spillovers to test for the market effects of Chinese influenza indices on the CSI300 (equity markets), the US/RMB exchange rate (foreign exchange markets), Bitcoin (as a measure of alternative investments in the form of cryptocurrency markets) and commodity markets, as considered through the use of gold, oil and soybean markets. Further informational benefit is provided through the addition of specific indices measuring both coronavirus and face masks. Such indices are developed from the financial performance of corporate entities where their central business practice is based on the R\&D, production and sales and products that are directly related to products relating to influenza, coronavirus and the production of face masks. Testing is repeated across different model specifications for added methodological robustness.

\section{Insert Figures 1 and 2 about here}

Figures 1 and 2 present evidence of the number of countries which have been affected to date and the sharp growth in the number of confirmed cases and deaths as reported by the World Health Organization (WHO). The rapid deterioration of international conditions has been largely attributed to a lack of synchronisation of the global response. Evidence suggests that countries with the best response rates made the tough decisions to close borders quite early on, while others have pointed to the fact that the presence of female leaders was a particularly important contributing factor to the success of the response. The decision to close borders and reduce the movement of people has severely impacted a number of economic measures as the spread of coronavirus began to escalate (Corbet et al. [2020]). While the contagion effects of the pandemic began to take its toll on economic conditions, financial markets responded in a number of unexpected ways. For example, evidence suggests that the price of stocks that were unlucky enough to share name characteristics

with 'coronavirus' suffered substantial and significant deterioration in line with the escalation of the pandemic (Corbet et al. [2020]).

Insert Figures 3 and 4 about here 
The sharp deterioration of economic conditions is presented in both Figures 3 and 4 where we consider the purchasers manufacturers indices (PMI) and stock market performance respectively for China, the US and Europe. It is interesting to note that while China experienced a sharp decline of the PMI in February 2020, it immediately increased to a level above its previous 12 months average in March 2020. The US has yet to present any evidence of forthcoming economic shocks within the PMI data, while data suggests that Europe suffered the same economic shock as China one-month later. When comparing the stock market responses in Figure 4, we clearly observe the lagged responses in both the US and German stock markets as investors failed to appropriately grasp the scale of the forthcoming economic reverberations inherent in the COVID-19 pandemic. Whereas, in Chinese markets, we can identify two significant periods of decline, the first in mid-January 2020 as the number of confirmed cases sharply increased in China while the Chinese government re-enforced counteractive measures to respond, while after a period of market growth, the Shanghai Stock Exchange fell sharply throughout March 2020 as signals of deep economic repercussions increased along with fears of a revival in the reproductive rates of the pandemic in the form of a second wave. Further, in an incredible sequence of events, primarily due to the collapse in the demand for oil, combined with a number of international geopolitical issues, the price of West Texas Intermediate futures turned negative as increased supply and reduced storage capacity hindered standard market operations, leading to a scenario where an investor would 'receive' in excess of $\$ 40$ per barrel to buy a May 2020 WTI futures contract for near month delivery. From Figure 5 we can clearly observe evidence of this extreme situation of contango. This scenario presented evidence of some of the sharp, abnormal volatility effects that had been generated within the COVID-19 pandemic. However, the sources and directions of these volatility spillovers can provide rich information for investors and policy-makers alike when preparing for future deterioration in circumstance, or indeed, future pandemics, should they arise.

\section{Insert Figure 5 about here}

Our results not only show that COVID-19 has had a significant impact on Chinese financial markets, as has been broadly identified across a rapid developing area of research, but in a novel finding to date, this research indicates that COVID-19 has had a substantial effect on the Bitcoin market. This result is specifically identified through the use of the indices relating directly to 
traditional influenza, coronavirus and face masks, the construction of which is discussed above. Further, each index represents the effects of COVID-19 on Chinese financial markets as measured through real-time investor sentiment. In an expected result, both the coronavirus and influenza indices directly influence the face mask index as measured by directional volatility spillovers. We also identify evidence of strong volatility spillovers from the coronavirus/influenza towards Chinese gold and oil futures markets during the pandemic, presenting evidence of the existence of traditional flight-to-safety channels during this time. However, the existence of both significant and substantial coronavirus/influenza spillovers to the Bitcoin market during the entire sample period analysed is of particular interest. One explanation for this outcome could be sourced in the education schemes that have been developed and progressed by the Chinese Communist Party to educate the population of China about the nature and future of digital currencies ${ }^{1}$. Such government support has provided substantive confidence in these rapidly developing digital technologies. Further analysis identifies that in the very early stages of the COVID-19 outbreak, it became clear that the coronavirus index possessed a far more substantial, pronounced and persistent impact on financial markets than that of the traditional and long-standing influenza index. This presented a signal of the deep-rooted economic, social and geopolitical issues that COVID-19 presented for the global population. Based upon multiple robustness checks, our results remain unchanged.

The remainder of this paper is structured as follows: previous literature that guides the development of our selected hypotheses are summarised in Section 2. Section 3 presents a thorough explanation of the wide variety of data used in this analyses, while Section 4 presents a concise overview of the methodologies utilised to analyse the relevant hypotheses. Section 5 specifically investigates the interactions between Chinese financial markets and other traditional financial market asset classes, while Section 6 concludes.

\section{Previous Literature}

Our research focuses directly on the analysis of volatility spillovers during the period surrounding the development of the COVID-19 pandemic, with particular emphasis on the influenza and coronavirus indices and their influence on traditional financial market asset volatility. Diebold and Yilmaz [2012] used a generalised vector autoregressive framework in which forecast-error variance

\footnotetext{
${ }^{1}$ An example of such material is available at: https://mp.weixin.qq.com
} 
decompositions are invariant to the variable ordering, to provide a measure of both the total and directional volatility spillovers. Using data on US stock, bond, foreign exchange and commodities markets, from January 1999 to January 2010, evidence suggested that the strongest volatility spillovers were sourced within stock markets upon other markets after the collapse of Lehman Brothers in September 2008. This research, while providing a significant advance of technique, found its sources in the works of Baillie and Bollerslev [1991], Susmel and Engle [1994] and Koutmos and Booth [1995], who had examined multi-frequency and cross-market spillovers in foreign exchange and equity markets respectively. Regional volatility has since been examined in Japan (Kim and Rhee [1997]; Ng [2000]); the United States (Tse [1999]); South Korea (Pyun et al. [2000]); Hong Kong (Gannon [2005]); Europe (Baele [2005], Fernandez-Rodriguez et al. [2015]); Taiwan (Lin [2006]); Canada (Krause and Tse [2013]), the United Kingdom (Antonakakis et al. [2016]) and in consideration of the BRICs in its entirety (Bekiros [2014]; Syriopoulos et al. [2015]; Mensi et al. [2016]). Further, Balli et al. [2015] identified significant spillover effects from developed markets to emerging markets.

Within our selected research methodology, we consider multiple traditional financial assets to test for the presence of volatility transmission and spillovers. To date, a number of effects have been identified with regards to the gold and cryptocurrency-based contagion effects sourced within the COVID-19 outbreak (Corbet et al. [2020]); and side-effects relating to name association (Corbet et al. [2020]). Specifically, their selection process was based on the findings of previous work establishing the existence of theoretically robust interlinkages. Here we consider the relationships between the performance of companies with influenza and coronavirus-dependant business structures and the broad equity index as represented by the CSI300, based on the prior works of Baele [2005], Diebold and Yilmaz [2009], Singh et al. [2010], Erdogan et al. [2013], Yarovaya et al. [2016], Smimou and Khallouli [2016], Bhuyan et al. [2016] and Shahzad et al. [2017]. Further, we consider interlinkages between COVID-19 and commodities as represented by gold, oil and soybeans. Corbet et al. [2020] previously identified substantial contagion effects sourced from the recent coronavirus outbreak upon both gold and oil markets. The addition of soybeans as a central commodity was based on China being the world's largest importer ( $\$ 39.6$ billion USD in 2017 , representing twothirds of the world's demand), with usage being driven by the product's importance as food for animals being bred for the growing demand for protein, but also as a replacement for traditional carbohydrates such as pasta and rice. Further support can be sourced from the works of Ham- 
moudeh et al. [2004], Malik and Hammoudeh [2007], Bhar et al. [2008], Malik and Ewing [2009], Du et al. [2011], Sadorsky [2012], Antonakakis and Kizys [2015], Kumar [2017], Bouri et al. [2017] and Lau et al. [2017]. Spillovers, persistence and the effects of volatility on real economic data and energy markets are other research fields that provide particular value to our work (as per Greasley and Oxley [1999], Oxley [2002], Fatai et al. [2004], Ma et al. [2008, 2009] and Zhao et al. [2010]). Another important channel through which contagion can spillover is foreign exchange markets, which have been found to be the case in Hong [2001], Do et al. [2016], with further evidence provided by the intra-day seasonality of transacted limit and market orders in the DEM/USD markets (Cotter and Dowd [2010]). Finally, we test for the presence of spillovers and the growing cryptocurrency sector, specifically Bitcoin, with previous works establishing contagion channels through multiple avenues as the product has matured since its initial development in 2009 (Yi et al. [2018]; Corbet et al. [2018]; Corbet et al. [2018]; Akyildirim et al. [2019]; Katsiampa et al. [2019a]; Katsiampa et al. [2019b]; Ji et al. [2019]; Guesmi et al. [2019] and Corbet et al. [2020]).

The transmission effects and spillover of fear is also found to be a central topic in guiding our research methodology and design. Tsai [2014] found that the US stock markets shows three periods during which its net spillover effect exceeds zero: the period prior to 1997, the dot-com bubble from 2000 to 2002, and the subprime mortgage crisis and Lehman Brothers bankruptcy from 2007 to 2008, where the developed fear index correlates significantly with the spillover of the US stock market into other markets. Hameed et al. [2010] documented inter-industry spillover effects in liquidity, which are likely to have been sourced in binding capital constraints, but followed periods of substantial decline in market valuation. Such results echo that of Lee and Rui [2002] who had found that there exists a positive feedback relationship between trading volume and return volatility in New York, Tokyo and London-based stock returns, where US financial market variables were found to contain extensive predictive power for UK and Japanese financial market variables. Other specific uses of spillover methodologies have incorporated research based on quantitative easing effects (Meegan et al. [2018]), terrorist attacks and aviation disasters (Corbet et al. [2018]; Corbet et al. [2019]; Akyildirim et al. [2020]). Much of this work has been guided by research relating to the direct effects of volatility transmission and contagion as measured through dynamic correlation analyses (Syllignakis and Kouretas [2011]) and broad behaviour through extreme financial market events. A variety of behavioural differences have already been identified, such as that found in the work of Bialkowski et al. [2006] who identified that spillovers from the US stock market to the UK, 
Japanese and German markets are more frequent when the latter markets are in a crisis, or an extreme volatility regime, while Liu [2014] found that extreme downside movements of the S\&P 500 and Nikkei 225 are significantly predictive for the likelihood of extreme downside movements in all the investigated Asia-Pacific markets. The 2007 financial market crises was identified as a particularly significant outlier event driving substantial contagion and spillover effects around the world (Longstaff [2010], Kim et al. [2015], Xu et al. [2018]).

While considering our methodological selection, we also considered much research that provides preemptive structural warnings with regards to broad issues surrounding simplistic methodological errors. We considered the work of Bae et al. [2003] to be particularly important, when identifying that contagion is predictable and depends on regional interest rates, exchange rate changes, and conditional stock return volatility, while Corsetti et al. [2005] found that the result of 'no contagion, only interdependence' stressed by recent contributions is due to arbitrary and unrealistic restrictions on the variance of country-specific shocks. Specifically, Pesaran and Pick [2007] sheds doubt on the general validity of the correlation-based tests of contagion recently proposed in the literature which do not involve any market specific variables.

\section{Data}

We obtain the data from the WIND database, which is the largest financial data provider in China. $^{2}$ In this paper, we use the 5-minute high frequency data for empirical analysis to best attempt to capture the volatility dynamics of different financial assets during the COVID-19 pandemic. Variables included in the analysis are: the coronavirus index, influenza index, face mask index, CSI 300 index, gold futures price, oil futures price, soybean futures price and US Dollar/RMB spot exchange rate, and Bitcoin (BTC) price. A time series plot of these series as originally measured is provided in Figure 6. A number of both sharp and significant price movements are identifiable. Particularly protracted declines in the value of the CSI300, gold and oil are evident within March 2020 , which is also evident in the volatility of returns, which are computed by taking first differences of the natural logarithms for each index or price, and are presented in Figure 7. During the same period of time, there are episodes of exceptional volatility in Bitcoin, where the price falls from over

\footnotetext{
${ }^{2}$ The WIND database is widely used for research topics related to China studies, for example see Liu et al. [2019] and Allen et al. [2019].
} 
$\$ 9,000$ to almost $\$ 4,000$ in two distinct and sharp declines. While such pronounced behaviour in equity and commodity markets can be attributed directly to events relating to the severity of the COVID-19 pandemic, the Bitcoin price collapse is somewhat unique. One possible reason for this movement has been attributed to the behaviour of leveraged traders (up to 100:1 leverage has been provided), as evidenced in substantially elevated trading volumes (almost $\$ 1$ billion dollars) and opaque pricing behaviour on the BitMEX exchange, which has been long-associated with the provision of leveraged-cryptocurrency trading ${ }^{3}$. The descriptive statistics for each logarithmic return series are presented in Table 1, adding further statistical support to the exceptional volatility of Bitcoin in comparison to other selection variables, with pronounced negative skewness and elevated kurtosis, with similar characteristics are also presented in the soybean market.

\section{Insert Figures 6 and 7 about here}

In this paper, we specifically select three important concept-based indices, denoted as the coronavirus index, the influenza index and the face mask index from the Wind database for our empirical analysis, as these indices allow us to explore market investors' reactions to the COVID-19 outbreak ${ }^{4}$. The Wind database develops a number of concept-based stock price index for Chinese market. The Wind Concept Index is a group of indices based on market hot spots, related topics, and capital market needs to meet specific concepts. The Wind Concept Index is an equal-weighted index that consisting of only A-share stocks in the Shanghai Stock Exchange (SSE) and Shenzhen Stock Exchange (SZSE). Based on the theme of the concept index, Wind database screens the stocks for the relevant industrial chain links and characteristics, taking into account of the turnover, market quotation, and the transaction characteristics such as linkage to determine the final sample ${ }^{5}$. Both SSE and SZSE are open five days per week for 4 hours per day: 9:30am-11:30am (morning session) and 1:00pm-3:00pm (afternoon session) local time. Hence, all three COVID-19 related indexes are

\footnotetext{
${ }^{3}$ BitMEX further claimed that during the same period, the exchange was subjected to a planned DDoS attack leading to substantial technological faults.

${ }^{4}$ The Wind Database is a dedicated system designed to provided accurate and real-time information, as well as sophisticated communication platforms for financial professionals. In China, the company serves more than $90 \%$ of financial institutions including hedge funds, asset management firms, securities companies, insurance companies, banks, research institutions, and government regulatory bodies. Overseas, Wind serves $70 \%$ of Qualified Foreign Institutional Investors (QFII). The company's data are frequently quoted by Chinese and international media, in research reports, and in academic papers.

${ }^{5}$ The Wind Concept Index has a basis point of one thousand.
} 
only available during market trading hours.

\section{Insert Table 1 about here}

The availability of the face mask index determines the starting date for our analysis, as it only becomes available on 05 February 2020. Hence, our sample data runs from 05 February 2020 to 12 May 2020 at the 5-minute frequency with 1982 observations $^{6}$. In each day, we select the data when the two Chinese stock exchanges are open during the two trading sessions (e.g., 9:30am11:30am and 1:00pm-3:00pm). To align with the face mask index, we then obtain all the data for the same period each day at the local time. The coronavirus index is used as the main proxy to measures the effects of COVID-19 virus in financial markets. The coronavirus index is created using an equal weight approach including 110 publicly listed Chinese companies that are heavily involved in producing diagnostic reagents, vaccines, antibiotics, antivirals, and masks related to pneumonia. ${ }^{7}$ The Coronavirus index shows how investors pursue the investment opportunities in the related companies. The influenza index is also considered as an alternative proxy to measure of the COVID-19 virus from a Chinese financial market perspective. The influenza virus is widely known as an acute respiratory infection, which is highly contagious and spreads quickly. Wind database creates a special concept-based stock price index-the influenza index, which comprises 35 listed A-share companies from that are involved in producing involve cold medicines, vaccines, $R \& D$ and manufacturing, to track the performance of the related companies ${ }^{8}$. Face masks have experienced an unprecedented surge in global demand since the outbreak of COVID-19. We consider this special type of product in our analysis as it plays a critical role in preventing respiratory infection. Many factories that usually made other products switched to making masks to meet the unprecedented demand with the coronavirus outbreak in China. We use the face mask index (also known as Antiseptic Gauze index) that includes 37 listed Chinese companies in the field of producing face masks and raw materials from SSE and SZSE. The face mask index simply provides a measure of the performance for the face masks producing industry after the outbreak of the COVID-19.

\footnotetext{
${ }^{6}$ We exclude the missing values during the sample period. In addition, the Chinese stock markets closed for Lunar New Year break from 24 January 2020 to 03 February 2020.

${ }^{7}$ The 5 minute coronavirus index is first available on 23 January 2020, and than the Chinese stock markets close for Lunar New Year break until 03 February 2020.

${ }^{8}$ The 5-minute influenza index is available from 02 November 2017.
} 
Apart from the above three COVID-19 related indices, we consider the coronavirus effects on traditional stock, commodity (agriculture, energy and precious metal), foreign exchange and cryptocurrency markets. In this paper, we use the CSI 300 stock index as indicative of trends in both of SSE and SZSE. The CSI 300 is a capitalisation-weighted stock market index designed to measure the performance of the top 300 stocks traded on SSE and SZSE. We select the Chinese soybean, oil, gold futures contracts, which are traded on the Dalian Commodity Exchange, Shanghai International Energy Exchange and the Shanghai Futures Exchange, respectively. The US Dollar-RMB spot rate is traded on the China Foreign Exchange Trade System (CFETS) to capture the effects on foreign exchange market. In addition, the BTSP Bitcoin price is used to represent the cryptocurrency market. As Bitcoin is traded 24 hours per day, we can match the Bitcoin prices using the local Chinese stock exchange time.

\section{Methodology}

Diebold and Yilmaz [2012] develop a spillover measure based on forecast error variance decompositions from a generalized VAR framework. In this seminal paper, the covariance matrix is time-invariant and is estimated under either the Cholesky factorization or generalized decomposition. It is widely documented that time series of financial asset returns often exhibit the property of volatility clustering and asset correlations also tend to vary over time especially in turbulent markets. Gamba-Santamaria et al. [2017], construct volatility spillover indexes Diebold and Yilmaz [2012] using a DCC-GARCH framework to model the multivariate relationships of volatility among assets. In their paper, the volatility is computed directly from the covariance matrix obtained from the DCC-GARCH model of Engle [2002], which has the advantage of avoiding the need to define the volatility. Antonakakis et al. [2018] investigate the volatility spillovers and co-movements between WTI and major oil \& gas firms stock prices using the spillover index approach of Diebold and Yilmaz [2012] and the dynamic conditional correlation model of Engle [2002]. More recently, Antonakakis et al. [2019] employ the time-varying parameter (TVP)-VAR-based approach of Antonakakis and Gabauer [2017] to generate the spillover indices of Diebold and Yilmaz [2012] and the DCC-GARCH t-Copula model of Patton [2006], to examine the dynamic spillover among the implied volatilities of oil and fourteen different asset indices. In particular, the TVP-VAR approach of Antonakakis and Gabauer [2017] improves the methodology of Diebold and Yilmaz [2012] with-

out needing to arbitrarily set a window size to carry out the rolling window estimation. A growing 
number of studies have adopted the TVP-VAR approach to explore transmission mechanism including Antonakakis et al. [2018] and Gabauer and Gupta [2018] Antonakakis et al. [2019]. In this paper, we follow Gamba-Santamaria et al. [2017], Antonakakis et al. [2018] and Antonakakis et al. [2019] to use a combination of the DCC-GARCH type framework and a TVP-VAR approach of Antonakakis and Gabauer [2017] to investigate the dynamic volatility spillovers among a number of Chinese financial markets as well as Bitcoin.

\subsection{Volatility spillover index}

Antonakakis and Gabauer [2017] extend the spillover index approach of Diebold and Yilmaz [2012] by allowing the variances to vary via a stochastic volatility Kalman Filter estimation approach to explore the transmission mechanism in a time-varying fashion. A TVP-VAR(1) model with timevarying volatility can be written as follows,

$$
\begin{aligned}
\boldsymbol{y}_{t} & =\beta_{t} \boldsymbol{z}_{t-1}+\boldsymbol{\epsilon}_{t} \quad \epsilon_{t} \mid \boldsymbol{F}_{t-1} \sim \mathrm{N}\left(0, \boldsymbol{S}_{t}\right), \\
\operatorname{vec}(\boldsymbol{\beta}) & =\operatorname{vec}\left(\boldsymbol{\beta}_{t-1}\right)+\boldsymbol{v}_{t} \quad \varepsilon_{t} \mid \boldsymbol{F}_{t-1} \sim \mathrm{N}\left(0, \boldsymbol{R}_{t}\right),
\end{aligned}
$$

where $\boldsymbol{y}_{t}$ and $\boldsymbol{z}_{t-1}=\left[\boldsymbol{y}_{t-1}, \ldots, \boldsymbol{y}_{t-p}\right]^{\prime}$ represent $N \times 1$ and $N p \times 1$ dimentional vectors. $\beta_{t}$ is a $N \times N p$ time-varying coefficient matrix and $\boldsymbol{\epsilon}_{t}$ is $N \times 1$ error disturbance vector and timevarying variance-covariance matrix of $\boldsymbol{S}_{t} \cdot \operatorname{vec}(\boldsymbol{\beta}), \operatorname{vec}(\boldsymbol{\beta})$ and $\boldsymbol{v}_{t}$ are $N^{2} p \times 1$ dimensional vectors and $\boldsymbol{R}_{t}$ is an $N^{2} p \times N^{2} p$ dimensional matrix. The time-varying coefficients of the vector moving average (VMA) is the fundamental of the connectedness index introduced by Diebold and Yilmaz [2012] using the generalized impulse response function (GIRF) and the generalized forecast error variance decomposition (GFEVD) developed by Koop et al. [1996] and Pesaran and Shin [1998]. The GFEVD can be interpreted as the variance share one variable has on others and it can be calculated as follows:

$$
\tilde{\phi}_{i j, t}^{g}(J)=\frac{\sum_{t=1}^{J-1} \mathbf{\Psi}_{i j, t}^{2, g}}{\sum_{j=1}^{N} \sum_{t=1}^{J-1} \mathbf{\Psi}_{i j, t}^{2, g}}
$$

where $\tilde{\phi}_{i j, t}^{g}(J)$ denotes the $J$-step ahead GFEVD. Using the GFEVD, variable $i$ transmits its shock 
to all other variables $j$, representing the total connectedness index of the network by:

$$
\begin{aligned}
C_{t}^{g}(J) & =\frac{\sum_{i, j=1, i \neq j}^{N} \tilde{\phi}_{i j, t}^{g}(J)}{\sum_{i, j=1}^{N} \tilde{\phi}_{i j, t}^{g}(J)} * 100 \\
& =\frac{\sum_{i, j=1, i \neq j}^{N} \tilde{\phi}_{i j, t}^{g}(J)}{N} * 100 .
\end{aligned}
$$

The spillovers of all variables $i$ to variable $j$, known as the total directional connectedness to others, is defined as :

$$
C_{i \rightarrow j, t}^{g}(J)-\frac{\sum_{j=1, i \neq j}^{N} \tilde{\phi}_{j i, t}^{g}(J)}{\sum_{j=1}^{N} \tilde{\phi}_{j i, t}^{g}(J)} * 100
$$

Similarly, the spillovers of all variables $j$ to variable $i$ (or the directional connectedness variable $i$ receives it from variables $j$ ), known as the total directional connectedness from others, is defined as:

$$
C_{i \leftarrow j, t}^{g}(J)=\frac{\sum_{j=1, i \neq j}^{N} \tilde{\phi}_{i j, t}^{g}(J)}{\sum_{j=1}^{N} \tilde{\phi}_{i j, t}^{g}(J)} * 100
$$

The net total directional connectedness $\left(C_{i, t}^{g}\right)$ is calculated using the total directional connectedness $\left(C_{i \rightarrow j, t}^{g}(J)\right)$ to others minus total directional connectedness from others $\left(C_{i \leftarrow j, t}^{g}(J)\right)$.

$$
C_{i, t}^{g}=C_{i \rightarrow j, t}^{g}(J)-C_{i \leftarrow j, t}^{g}(J)
$$

The sign of the net total directional connectedness illustrates whether a variable $i$ is driving the network $\left(C_{i, t}^{g}>0\right)$ or driven by the network $\left(C_{i, t}^{g}<0\right)$. The net pairwise directional connectedness is calculated in the bidirectional relationships:

$$
N P D C_{i, t}^{g}=\frac{\tilde{\phi}_{j i, t}^{g}(J)-\tilde{\phi}_{i j, t}^{g}(J)}{N} * 100
$$

The net pairwise volatility spillovers between markets $i$ and $j$ is simply the difference between the gross volatility shocks transmitted from variable $i$ to variable $j$ and those transmitted from variable $j$ to variable $i$. 


\subsection{DCC-GARCH t-Copula}

Copula functions can be used for modelling correlated random variables. Let $X_{i}$ be a random variable with a marginal distribution $F_{i}$ for $i=1,2, \ldots, n$. As Sklar [1973] shows, each distribution function $F\left(x_{1}, \ldots, x_{n}\right)$ can be represented as its marginal distribution by using a copula such as

$$
F\left(x_{1}, \ldots, x_{n}\right)=C\left(F_{1}\left(x_{1}\right), \ldots, F_{n}\left(x_{N}\right)\right) .
$$

An $n$-dimensional copula $C$ determined in $[0,1]^{n}$ can be written as

$$
C\left(u_{1}, \ldots, u_{N}\right)=F\left(F_{1}^{-1}\left(u_{1}\right), \ldots, F_{n}^{-1}\left(u_{n}\right)\right)
$$

for $\forall u_{i} \in[0,1], i=1, \ldots, N$. According to Patton [2006], copulas can be based on conditional distributions for estimating a DCC-GARCH $t$-copula model:

$$
\begin{aligned}
c\left(u_{1}, \ldots, u_{N} \mid \boldsymbol{R}_{t}, \eta\right) & =\boldsymbol{t}_{\eta}\left(F_{X_{1}}^{-1}\left(u_{1} \mid \bullet_{1}\right), \ldots, F_{X_{N}}^{-1}\left(u_{N} \mid \bullet_{N}\right)\right) \\
& =\int_{-\infty}^{F_{1}^{-1}\left(u_{1}\right)} \ldots \int_{-\infty}^{F_{N}^{-1}\left(u_{N}\right)} \frac{\Gamma\left(\frac{\eta+N}{2}\right.}{\Gamma\left(\frac{\eta}{2}\right)(\eta \pi)^{N / 2}\left|\boldsymbol{R}_{t}\right|^{1 / 2}}\left(1+\frac{1}{\eta} \boldsymbol{z}_{t}^{\prime} \boldsymbol{R}_{t}^{-1} \boldsymbol{z}_{t}\right)^{(\eta+N) / 2} d z_{1}, \ldots, d z_{N}
\end{aligned}
$$

where $F_{X_{1}}^{-1}\left(u_{1} \mid \bullet 1\right)$ represents the conditional distribution and $\bullet$ represents the estimated parameters of the univariate GARCH model. The DCC model is applied to study the time-varying correlations of asset returns. The time-varying variance-covariance matrix $\boldsymbol{H}_{t}$ is defined as:

$$
\boldsymbol{H}_{t}=\boldsymbol{D}_{t} \boldsymbol{R}_{t} \boldsymbol{D}_{t}
$$

where $D_{t}=\operatorname{diag}(\sqrt{h 11, t}, \ldots, \sqrt{n n, t})$ is a diagonal matrix of square root conditional variances. $R_{t}$ is the dynamic conditional correlations based on the standardised residuals' conditional variancecovariances, $Q_{t}$, that are followed a $\operatorname{GARCH}(1,1)$ model of Engle [2002]:

$$
\begin{aligned}
\boldsymbol{Q}_{t} & =(1-a-b) \overline{\boldsymbol{Q}}+a \boldsymbol{z}_{t-1} \boldsymbol{z}_{t-1}^{\prime}+b \boldsymbol{Q}_{t-1} \\
\boldsymbol{R}_{t} & =\operatorname{diag}\left(\boldsymbol{Q}_{t}\right)^{-1 / 2} \boldsymbol{Q}_{t} \operatorname{diag} \boldsymbol{Q}_{t}^{-1 / 2}
\end{aligned}
$$

where $a$ and $b$ are positive scalar parameters satisfying $a+b<1$ to ensure stationarity. The 
DCC model is estimated under a multivariate Student-t distribution. The multivariate Student- $t$ distribution is applied as the normality assumption of the innovations is rejected for each volatility series.

\section{Results}

\subsection{The effects of the coronavirus indices on selected financial markets}

We first investigate how the coronavirus index affected Chinese stock, commodity, and foreign exchange markets, together with the largest cryptocurrency, Bitcoin, using the 5-minute return data. The structure of our selected methodologies and data-frequencies used to test our proposed hypotheses, along with related robustness tests are outlined in Table 2. An eight-variable VAR model is estimated including the coronavirus index, face mask index, CSI 300 index, gold futures price, oil futures price, soybean futures prices, US Dollar/RMB exchange rate and Bitcoin spot prices. Our prime interest is to explore the dynamic volatility spillovers between coronavirus and several selected financial markets, in order to understand the contagion effects of volatility shocks using the framework of Diebold and Yilmaz [2012], Gamba-Santamaria et al. [2017] and Antonakakis et al. [2019]. The results are based on vector autoregressions of order 4 and 10-day-ahead volatility forecast errors, which are the same as those used by Diebold and Yilmaz [2012]. ${ }^{9}$

\section{Insert Table 2 \& Figure 8 about here}

A substantial slow-down in economic activity has lead to a turbulent global financial market during COVID-19, primarily driven by the implementation of physical lock-downs across the world. We graphically examine the dynamic total connectedness plot as presented in Figure 8, where the spillover index changes over time. The general trend of the dynamic total connectedness index is slightly increasing. We find that the volatility spillovers first reach a peak in early February 2020, indicating that the initial outbreak of COVID-19 had quite a strong impact on different Chinese financial markets as a result of a nation-wide reaction taken to contain the rapid spread of COVID-19. The spillovers are found to have deceased slightly during mid- and late-February.

\footnotetext{
${ }^{9} \mathrm{We}$ also check for the sensitivity of all the empirical results to the choice of vector autoregressions order and forecast error horizons. Our results remain unchanged.
} 
The most interesting finding of the total connectedness plot refers to the recent decline in oil and Bitcoin prices. The spillover index begins to increase sharply in early March and reaches a peak between 08 March and 13 March as geopolitical issues between Saudi Arabia and Russia began to influence to price of oil, and the crash of Bitcoin prices from over $\$ 9,000$ to $\$ 4,000$ between March 12 and 13. The geopolitical issues that sparked the volatility observed in oil prices began during the break-down in dialogue between key oil producers over proposed oil-production cuts in response to decreased demand due to the outbreak of COVID-19 pandemic. Calculated volatility spillovers decline temporarily after mid-March and remain quite stable until early April. US WTI crude oil futures for May plunged below zero on 20 April for the first time in recorded history. In late-April, the dynamic total connectedness index increases dramatically again when the global financial markets face more turmoil. During the current pandemic, the dynamic total connectedness index changes as a combination of factors, including the coronavirus outbreak, political instability in oil markets, and the crash of Bitcoin prices, generated substantial fear across multiple financial markets.

\section{Insert Figure 9 about here}

The dynamic net directional connectedness index is calculated as the difference between gross volatility shocks transmitted to and those received from all other markets and such an index is shown as Figure 9. There are three interesting findings. First, we pay special attention to the dynamic net connectedness of the coronavirus index as presented in Figure 9a. The dynamic net volatility spillover of coronavirus is positive during the entire sample period. The net directional connectedness of coronavirus is defined as the volatility shocks transmitted from the coronavirus index to different financial assets minus the volatility shocks received by the coronavirus index from all other assets. Our results, therefore, show that volatility spillovers from the coronavirus index to all other financial assets play a dominant role. In other words, the coronavirus index is a volatility transmitter. Second, the net volatility spillover of coronavirus is found to be decreasing throughout the analysed period. The nationwide lock-downs imposed by the Chinese government were found to be both effective and successful while attempting to slow down the rapid spread of COVID-19. There are several major episodes of net volatility spillovers taking place from the coronavirus index to other indices and markets as shown in Figure 9. Thirdly, we observe that the selected face mask 
index, the price of gold, oil, and that of Bitcoin are all found to be net volatility receivers as they transmit less risks than they receive from other markets.

\section{Insert Figure 10 about here}

The dynamic net pairwise directional connectedness between the coronavirus index and other financial markets is shown as Figure 10, where the estimate of pairwise spillover index is shown on the $y$ axis for every pair considered. A number of interesting empirical findings are noted as follows. The volatility shocks in the coronavirus index spill-over mostly to the face mask index, CSI300 index, gold, oil, and Bitcoin price as the corresponding net pairwise connectedness indices from the coronavirus index to each of the index or asset price are positive during the sample period. A positive pairwise connectedness would indicate that a volatility shock transmitted from the coronavirus index to the other market was larger than in the opposite direction. Therefore, a positive pairwise connectedness index implies that the coronavirus influence an index or asset price. There are found to exist strong volatility spillovers from the coronavirus index to the face mask index during the entire sample for our analysis as the net pairwise directional connectedness index remains positive. While the influenza index is found to generate small effects, the coronavirus index is found to be a substantial volatility transmitter upon companies that manufacture face masks due to government enforcement and legislative procedures introduced for the safety of the population. The widespread usage of disposable masks has been shown to be effective in controlling the incidence rate of COVID-19 infections. For example, China, Japan, and South Korea have all been presented as strong examples of states that have promoted widespread usage of face masks together with intensive strategies thorough testing, effective contact tracing, mandated social distancing, all of which have been found to contain risk. Some European countries also require their residents to

wear face masks, for example, Austria, the Czech Republic and Slovakia. The phenomenon of volatility spillover from the coronavirus to face mask indices clearly demonstrate that the spread of COVID-19 has dramatically increased the demand of face masks worldwide.

There is clear evidence to support the view that the coronavirus index impacts the top 300 stocks traded on Chinese stock markets. In Figure 10, we observe strong volatility spillovers from the coronavirus index to the CSI 300 index as the dynamic net pairwise directional connectedness index is generally positive. Here we provide a meaningful explanation why the volatility was trans- 
mitted from the coronavirus index to the CSI300 stock index. Since the breakout of COVID-19, many CSI300 listed companies have made great efforts to fight the virus by rapidly shifting their production lines from cars and jet engines to face masks. Sinopec, also known as known as China Petroleum \& Chemical Corp., obtained mask-making equipment by setting up eleven production lines. Gree, as the world's largest air conditioner maker, started to manufacture up to two million N95 surgical masks and surgical masks daily. Furthermore, the Midea Group is a Chinese electrical appliance manufacturer also listed on the Fortune Global 500. The company created a new production line that can make 200,000 face masks per day, while BYD, which is China's biggest electric vehicle maker, has built a plant in Shenzhen to produce five million masks and 300,000 bottles of disinfectants per day to tackle the growing COVID-19 outbreak. BYD is now becoming one of the world's largest face mask producers.

A similar pattern is observed for the relationship between coronavirus and gold markets. During the current pandemic, gold has received more volatility shocks from the coronavirus index than it transmits. Our findings support the flight-to-safety phenomenon from coronavirus related shocks to the gold market as there is an increasing demand for gold during the turmoil. There will be a shift to investing in safe-haven assets like gold from risky assets where gold is traditionally regarded as a safe-haven (see Baur and Lucey [2010]). When focusing on the relationship between coronavirus and oil, the dynamic net pairwise directional connectedness index is positive during the sample period. Our results indicate that the volatility shocks during the outbreak of the coronavirus pandemic has directly and significantly influenced the oil market. Oil demand in China fell substantially due to the contraction in oil consumption, and major disruptions to global travel and reduced economic activity.

When focusing on the dynamic net pairwise directional connectedness from the coronavirus index to soybean futures prices, volatility spillovers reach a maximum value in early February and then gradually decline, yet remain consistently positive at the end of March. Between late March and mid-April, the pairwise connectedness index is negative, indicating soybean influences the coronavirus. However, the spillover index recovers quickly to a positive value. Overall, the outbreak of COVID-19 has quite strong impacts on the market for soybeans. There is clear evidence that the coronavirus index effects the most important agricultural futures market in China, where the volatility shocks in the coronavirus transmit to soybean. The volatility spillover results coincide with strong demand for food, together with the disruption to food supply chains amid the pandemic, 
with panic-buying and stockpiling behaviour of the population during the initial panic at the start of the pandemic. The effects on exchange rates are not found to be significant throughout the period analysed.

In a particularly interestingly observation, we also identify strong evidence that the coronavirus index significantly influences the volatility of Bitcoin during the pandemic, as the dynamic net pairwise directional connectedness index is found to be consistently positive. The coronavirus is a volatility transmitter to Bitcoin. Such findings may help to explain Bitcoin's highly volatile nature during the pandemic. On 12 March 2020, the price of Bitcoin fell almost 50\% in one day, largely attributed to significant market issues on the BitMEX exchange, which has been long associated with leveraged traders. Even considering the presence of this abnormal price decline, in the days thereafter the collapse of Bitcoin prices from over $\$ 9,000$ to almost $\$ 4,000$, were followed by the price of Bitcoin increasing sharply, reaching $\$ 10,000$ in May 2020. The identification of pairwise directional connectedness between the coronavirus index and Bitcoin is a novel findings to date. This result specifically supports the presence of a flight-to-safety phenomenon in Bitcoin markets during the market turbulence as Bitcoin acts as a safe haven for Chinese investors. Due to a number of substantial geopolitical issues and elevated prices in both agricultural, energy and precious metal commodities, which are found to present historical evidence of flight-to-safety behaviour, the sharp collapse in Bitcoin prices presented quite a timely opportunity for some investors to enter this cryptocurrency market at prices substantially below multi-year averages.

\section{Insert Table 3 about here}

We also present the maxima, minima, means and standard deviations of the corresponding pairwise spillover estimates in Table 3 for each pair. From this table, we find that the volatility spillover effects from the coronavirus index to the face mask index are greater than the other asset prices followed by gold, oil and Bitcoin markets. It is interesting to note that the coronavirus related shocks transmit volatility shocks to the three important commodities-gold, oil and Bitcoin. Overall, we find overwhelming evidence that the coronavirus significantly and substantially effected Chinese financial markets and Bitcoin during the pandemic. 


\subsection{The effects of influenza indices on selected financial markets}

Compared with Section 5.1, we are particularly interested in exploring how the traditional influenza index effects stock, commodity, foreign exchange and cryptocurrency markets using the 5-minute data for the same sample period. The influenza index is selected as an alternative proxy measure for the COVID-19 virus in this paper, focusing on companies that would have been particularly central to the traditional seasons of influenza that would have been expected prior to the outbreak of COVID-19. Therefore, an eight-variable VAR model is estimated including the influenza index, face mask index, CSI 300 index, gold futures price, oil futures price, soybean futures prices, US Dollar/RMB exchange rate and Bitcoin spot prices.

\section{Insert Figure 11 about here}

As we can see from Figure 11, the dynamic total connectedness index is time-varying. The dynamic total connectedness index has an increasing trend and it reaches a peak when the recent oil price war started on 08 March 2020. The total volatility spillover shows an increase in range volatility interdependence between the markets after April. The combination of COVID-19 with the recent oil price war certainly lead to the increased financial volatility, at least for Chinese markets.

\section{Insert Figure 12 about here}

The dynamic net directional connectedness index, which shows the difference between gross volatility shocks transmitted to and those received from all other markets, is shown as Figure 12. As we can see, the net directional connectedness index for influenza and CSI300 are volatility transmitters. The dynamic net directional connectedness index for influenza indicates how much each market contribute to the influenza in net terms from a time-varying perspective. The dynamic net spillover index for influenza is presented as Figure 12a. It is clear that volatility spillovers from influenza index to other considered assets, outweigh the directional spillover effects to other investment assets in the transmission process. This provides evidence that the influenza index is a volatility transmitter during the current pandemic. The volatility spillovers first peak in early February at the initial breakout of COVID-19 and then volatility spillovers remain positive for the remaining sample period. Overall, this result suggests that the influenza index presents significant influences upon both Chinese financial markets and Bitcoin. 


\section{Insert Figure 13 about here}

The dynamic net pairwise directional connectedness from influenza to the other markets is presented as Figure 13. Compared to the results for the coronavirus, reported in section 5.1, we find the dynamic net pairwise spillovers from the influenza index to face mask, gold, oil and soybean are generally positive during the sample period. It can be interpreted that a positive pairwise connectedness index from the influenza index would indicate that volatility shocks transmitted from the influenza index to each individual asset are larger than vice versa. Hence, the influenza index impacts the risks of these mentioned financial markets by being a volatility transmitter. The volatility shocks in the influenza index mostly spill over to the face mask index when we compare the net pairwise directional connectedness index on the $y$-axis for each pair. More specifically, we observe episodes of volatility spillovers towards to the face mask index, where the corresponding pairwise spillover index reaches a maximum in early March and remains positive during the sample period.

The pairwise connectedness index for the influenza and CSI300 pair is found to be mostly negative, indicating strong volatility spillovers towards the influenza index from the CSI300 index. The influenza index is found to be influenced by the CSI300 index and the influenza index is, therefore, a net volatility receiver from the CIS300 index, where these results are in contrast to those observed in a similar analysis of the coronavirus index, which is found to have had stronger impacts on the top 300 traded stocks in Chinese stock markets. Similar to the coronavirus, the influenza index influences both gold and oil risks, but not on a scale observed during the recent pandemic. Furthermore, the relationship between the influenza index and soybeans is found to be similar to that experienced during the coronavirus pandemic, specifically at points in time where there was evidence of panic-buying in Chinese markets. Within these results, one of the key findings remains that of positive directional spillovers on Bitcoin, presenting more evidence of safe-haven behaviour.

\section{Insert Table 4 about here}

Table 4 also shows the maxima, minima, mean and standard deviations of the individual dynamic pairwise spillover estimates. We find that most volatility shocks in the influenza index spill over to 
face masks, gold, oil and Bitcoin if we compare the mean estimates of dynamic pairwise spillovers. From this, we find that the influenza index significantly impacts upon the risks of several Chinese financial markets by transmitting directional volatility shocks, for example, to that of gold, oil, soybean, and most unexpectedly, Bitcoin. Such a result provides methodological robustness towards the results provided within our earlier provided coronavirus index analysis. It is important to next test as to what differential effects can be uncovered through analysis of the differentials between the coronavirus indices and that of the influenza indices, that is, what specific differentials in market effects, as measured through investor sentiment, has the outbreak of the COVID-19 pandemic generated when compared to traditional Chinese-sources influenza outbreaks?

\subsection{Comparing coronavirus \& influenza effects on financial markets}

Section 5.1 and Section 5.2 investigate the volatility spillover between the coronavirus/influenza indices and key financial markets, and the corresponding results from these two sections show that risks within both coronavirus and influenza indices are found to influence the financial risks of several markets. In this section, we, therefore, compare the net pairwise directional connectedness of the coronavirus and influenza indices on the same financial market by using the pairwise spillover of coronavirus (as presented in Figure 10) less the pairwise spillover of influenza (as presented in Figure 13). The resulting difference between the two pairwise spillover indices for a particular market is provided in Figure 14. A positive (negative) value in the differences of the two spillover indices indicates that the coronavirus (influenza) has more substantial impact on the volatility transmissions in a net form. We can therefore explore as to whether the coronavirus index or influenza index has played a more important role in the volatility transmission process towards our selected financial markets. An inspection of Figure 14 shows that the coronavirus index influences the risk to financial markets more than influenza index as the differences in the pairwise spillover indices are generally positive. The volatility transmission to the group of markets considered has been larger from the coronavirus index than from the influenza index.

\section{Insert Figure 14 about here}

Considering the particular markets, we first look at the differences in the pairwise volatility spillovers to the face masks as depicted in Figure 14a, where the differences between two pairwise 
spillover indices are positive during the entire sample period. This suggests that the coronavirus index contributes more volatility shocks to the face mask industry than those of the influenza index during the pandemic. It should be noted that both coronavirus and influenza indices are volatility transmitters to the face mask index. The differences between the two net pairwise spillover indices to the CSI300 stock market implies that the coronavirus index influences more of the top 300 traded stocks in China, and contributes more volatility shocks to the CSI300 index than that of the traditional, expected influenza season. As earlier identified, the influenza index is a net volatility receiver to the CSI300 index while the coronavirus index is a volatility transmitter.

The markets for both gold and oil are of particular interest during the pandemic. The coronavirus pandemic dominates the volatility transmission process to both the gold and oil market where the coronavirus index has a larger effect than the influenza index. This result further confirms that the coronavirus had a significant impact on on the Chinese oil futures market with demand falling sharply during the lock-down that quickly followed. Positive differentials in the calculated relationships between both indices and Bitcoin, provide further evidence of volatility transfer from the pandemic to the developing digital currency, supporting the view that there existed a flightto-safety during the the development of the epidemic as investors attempted to quantify the true nature of the risks that they were confronted.

\subsection{Robustness checks}

5.4.1. Coronavirus and influenza effects on financial markets based on a nine-variable model.

Using an eight-variable VAR model, we explored the volatility spillovers between coronavirus and other markets in section 5.1, and considered a similar model for the influenza index in section 5.2. The corresponding results suggest that both the coronavirus and influenza indices transmit volatility shocks to several important commodity markets including gold, oil, Bitcoin. In this section, a robustness check is undertaken by considering a nine-variable VAR model to investigate the potential contagion of shocks among financial markets. For this nine-variable model, we include the coronavirus, influenza, and face mask indices together with other financial markets.

\section{Insert Figure 15 about here}

We first present the net pairwise directional connectedness between coronavirus and other mar- 
kets in Figure 15. ${ }^{10}$ Several notable findings are presented as follows. Firstly, the pairwise spillover indices between coronavirus and individual financial market are positive during the whole sample period except for the soybean and foreign exchange rate markets. Secondly, Figure 15a presents an important finding where the coronavirus index transmits volatility shocks to the influenza index during the entire sample period. In other words, the coronavirus related stocks dominate the volatility transmission process to the influenza related stocks. Thirdly, the coronavirus index delivers volatility shocks to the companies associated with producing face masks and the top 300 listed companies in China as shown in Figure 15b and Figure 15c, respectively. Fourthly, coronavirus transmits volatility spillover effects to gold, oil and Bitcoin markets as clearly shown in Figures 15d, 15e and 15h.

\section{Insert Figure 16 about here}

The net pairwise directional connectedness between influenza and other markets is shown in Figure 16. We observe that the net pairwise directional connectedness indices are positive during the entire sample period for face mask, CSI300, gold, oil and Bitcoin. In these cases, the volatility spillovers from the influenza index to each of these market are higher than the volatility spillovers from each financial market to influenza. In particular, Figure 16b illustrates a different story under a nine-variable model for the CSI300 index. As previously shown in Figure 13b using an eightvariable model,the pairwise connectedness index for influenza-CSI300 pair is mostly negative. For soybean, the pairwise connectedness index remains mostly positive.

Overall, we find that most results from Figure 15 and Figure 16 coincide with those of results in Section 5.1 and Section 5.2. Both the coronavirus and influenza indices effect several financial markets in China together with the largest cryptocurrency market. There exists strong interlinkages among COVID-19 related indices and the other six financial markets.

\subsubsection{Comparing coronavirus \& influenza effects on financial markets using a nine-variable model}

In addition, we can also compare the volatility shocks of coronavirus and influenza to to other financial markets by using the appropriate pairwise spillover of coronavirus in Figure 15 less the

\footnotetext{
${ }^{10}$ For brevity, we do not report results of the total and directional net connectedness indices. These results are available from the authors upon request.
} 
pairwise spillover of influenza in Figure 16. We present the difference between the two pairwise spillover indices for a particular market in Figure 17.

\section{Insert Figure 17 about here}

For example, we use the estimate from Figure 15b minus Figure 16a to see the differences of the volatility shocks of coronavirus and influenza to the face mask market. A positive (negative) value in the differences of two spillover indices implies that the coronavirus (influenza) has more impact on the volatility transmission. As can be seen from Figure 17, the coronavirus index contributes the most volatility shocks for a wide range of financial markets compared to the influenza index, which is consistent with the conclusion drawn in Section 5.3 using an eight-variable model. This result further strengthens our aforementioned findings that coronavirus dominates in the volatility transmission process.

\subsection{Discussion}

Based on a broad range of carefully selected data, the identification of sentiment-induced, significant directional volatility spillovers from companies with primary business interests in the development of face masks and those involved at the front-line of the battle against the COVID-19 pandemic, along with a number of behavioural observations relating to investors has been shown to be particularly important. The COVID-19 pandemic has the properties of a black-swan event, where the rarity of the international shock can be observed in the lack of preparation evident in the statements of international corporate entities, who were caught unawares by the scale and speed of the outbreak. Focusing on the Chinese epicentre of the pandemic presents a number of very interesting observations. Prior to the identification of the 'mystery pneumonia' in Wuhan, evidence suggests that there were no prior related media announcements before 17 November 2019. Some news sources have stated the existence of social media posts and anecdotal evidence prior to this date. However, it is clear that the severity of the forthcoming pandemic was broadly missed by the international investment community. But even after considering the presence of COVID-19 in it's relative infancy in late 2019, evidence suggests that international financial markets did not consider the pandemic to be threatening. It is in January and February 2020 before the associated economic concerns generate panic throughout financial markets, similar in nature to the March 2008 collapse 
of Bear Sterns, when investors were faced with an opaque and unique inter-generational crisis. Evidence provided in this research suggests that Chinese investors responded in much the same manner as investors throughout a number of historical crises, by seeking short-term security in commodity markets. While evidence regarding shifting investment to soybean markets does not appear to be consistent throughout the period of analysis, directional spillovers of volatility are evident, and consistently flowing to both the markets for Chinese gold and oil futures. The former connection can be explained by a long-standing traditional safe-haven in gold markets, however, the latter can also deemed to be consistent with the realisation that an economic slowdown in China would lead to substantial collapse in demand for oil, where along with a number geopolitical episodes, is further reflected in the subsequent collapse of Brent crude and in a more extreme manner, West Texas Intermediate.

What is most interesting within these new results is that there is a significant relationship between the outbreak of the COVID-19 pandemic and directional volatility spillovers into the Bitcoin market. While digital currencies continue to develop at pace, Bitcoin remains synonymous with the market leading cryptocurrency in terms of both market capitalisation and trading liquidity. The Chinese government have, for a number of years, remained quite optimistic about the role that blockchain could have with regards to economic development and control over the broad technology, however, their stance with regards to cryptocurrencies has been quite distantly cautious. The Chinese state, in recent times, has censored posts against blockchain, however, the Chinese central bank stated its preference to instead restrict cryptocurrency trading. It would appear that dilution of control of monetary policy could be one reason as to why the Chinese government has taken this stance, which is quite reasonable due to the wide variety of issues that remain within the structure of Bitcoin and other related cryptocurrencies. Such digital assets also possess the threat of disrupting traditional Chinese monetary flows and economic platforms, not to mention transactions that flow outside sovereign and state control and the potential for investment losses and over-inflating bubbles. Headwinds have been observed in the natural advantage that the Chinese population have possessed in the creation of cryptocurrencies, primarily, the country's advantage with regards to technological innovation, and secondly, a close proximity to nations with cheap sources of power. Evidence of Chinese fuelled rallies in Bitcoin were as recent as October 2019, when the price of Bitcoin exceeded $\$ 10,000$ when President Xi Jinping stated that Beijing will increase investment in blockchain technology. An official within the China's central bank also stated that 
the blockchain technology could potentially offer help with the risk control of commercial banks and potentially increase lending opportunities for smaller domestic businesses. On the same day as this statement, technological shares relating to blockchain and cryptocurrency increased substantially to daily price limits in both Shanghai and Shenzhen. As the economic crisis associated with the COVID-19 pandemic continued to advance there was an observed softening of the firm stance that the Chinese government had taken with cryptocurrency. In late 2019 and throughout early 2020, it was reported by multiple media sources that the People's Bank of China had launched a cryptocurrency called the Digital Currency Electronic Payment (DCEP), which had been primarily the work of the largest four state banks and three telecoms companies within a stage-by-stage rollout. Central bank officials explained that the CBDC will use a two-tier system where both the central bank and these stated financial institutions will be legitimate issuers.

The timing of the announcement of DCEP is of broad interest. It is widely accepted that cryptocurrencies such as Bitcoin or Ethereum stand in contravention to central banks and legacy financial institutions. Some governments (including China) subsequently blocked cryptocurrencies and proceeded to ban initial coin offerings (ICOs) and exchanges from trading from servers in China or using the Chinese Yuan. Prior to the introduction of these regulations, over $70 \%$ of the world's Bitcoin were mined in China (Corbet et al. [2019]). The sequence and timing of such events appear to have generated an environment of support in which Chinese investor confidence in broad cryptocurrency, and in particular that of Bitcoin increased. In the face of the incredible level of adversity facing Chinese investors, it would appear that both the sequence and timing of these events created an environment in which Bitcoin offered a safe-haven to investors as both equity and traditional commodity markets attempted to identify the scale of the COVID-19 crisis.

\section{Concluding Comments}

While international financial markets attempted to rapidly quantify and forecast perceptions of risk and financial loss associated with the official WHO announcement of the international outbreak of the COVID-19 pandemic in late-2019, it became quickly evident that investors were faced with quite unique economic, geopolitical and social challenges. Chinese financial markets were the first to respond due to the initiation of the COVID-19 pandemic in Wuhan and the subsequent lock-downs of entire cities that quickly ensued. It was at this point that the wider international community understood the true nature of the issue to which it was confronted. Due to the elevated 
probability of recurrence of pandemics in the future due to the nature of the COVID-19 outbreak, it is important to understand the behaviour of investors in the aftermath of such events. One particularly novel way to investigate such behaviour is through the use of a number of related indices. We specifically identify such effects through the use of the indices relating directly to traditional influenza, coronavirus and face masks, built upon corporate entities where their central business practice is in the $\mathrm{R} \& \mathrm{D}$, production, sales and distribution of goods and services related to each sector. Furthermore, each index represents the effects of COVID-19 on Chinese financial markets as measured through real-time investor sentiment. Further analysis identifies that in the very early stages of the COVID-19 outbreak, it became abundantly clear that the coronavirus index possessed a far more substantial, pronounced and persistent impact on financial markets than that of the traditional and long-standing influenza index. This presented a signal of the deep-rooted economic, social and geopolitical issues that COVID-19 presented for the global population.

First, we need to understand how investors responded in the aftermath of news announcements. To do so, we focus specifically on volatility spillovers from our selected influenza and coronavirus indices, the direction and scale of which offer information as to the manner in which investors responded. Both the coronavirus and influenza indices are found to have directly influenced the face mask index as measured by directional volatility spillovers. As government sanctions escalated, the creation and sale of face masks was one of the first mandatory sanctions, therefore directly influencing sales and cash-flows. Further, we identify evidence of strong volatility spillovers from the coronavirus and influenza indices towards Chinese gold and Chinese oil futures markets during the pandemic, presenting evidence of the existence of traditional flight-to-safety channels during this time. It is important to stress the distinction between Chinese traded oil and the negative pricing experienced in the market for West Texas Intermediate in mid-April 2020. Interactions between both coronavirus, influenza indices and that of Chinese oil as measured by INE futures contracts is a particularly interesting observation. Market rules limit daily price movements to $10 \%$, and INE trading has halted during the most volatile days during this period. Such contracts were the first oil futures to be traded in China, the world's biggest oil importer, and spillovers generated from the outbreak of the COVID-19 pandemic would indicate behaviour similar to that of investors seeking a safe-haven in a similar manner to investment behaviour during the initial stages of the subprime collapse in 2007 and 2008. Similar spillovers into gold contracts add further support to this result.

Our results not only show that COVID-19 has had a distinct and lasting impact on Chinese 
agricultural, energy and financial markets, but we also identify that COVID-19 appears to have had a substantial and pronounced effect on the price of Bitcoin as measured through directional volatility spillovers. This result is found to be robust across alternative modelling structures. Chinese government education provision, with regards to the development and trading of digital currencies, appears to have provided substantive support and confidence in these rapidly developing digital technologies. While such use of digital currency as a short-term store of value will be supported by proponents and opportunistic governments, it will cause substantial alarm amongst a number of regulators and policy-makers who are aware of the broad-range and frequency of both complex and relatively simplistic fraud. Should the COVID-19 pandemic continue to evolve, or indeed, should another pandemic occur in the future, we must consider the role that cryptocurrencies could potentially play during periods of exceptional market stress.

\section{References}

Akyildirim, E., S. Corbet, M. Efthymiou, C. Guiomard, J. O'Connell, and A. Sensoy (2020). The financial market effects of international aviation disasters. International Review of Financial Analysis 69.

Akyildirim, E., S. Corbet, P. Katsiampa, N. Kellard, and A. Sensoy (2019). The development of bitcoin futures: Exploring the interactions between cryptocurrency derivatives. Finance Research Letters.

Allen, F., Y. Qian, G. Tu, and F. Yu (2019). Entrusted loans: A close look at china's shadow banking system. Journal of Financial Economics 133(1), 18-41.

Antonakakis, N., J. Cunado, G. Filis, D. Gabauer, and F. P. De Gracia (2018). Oil volatility, oil and gas firms and portfolio diversification. Energy Economics 70, 499-515.

Antonakakis, N., J. Cuñado, G. Filis, D. Gabauer, and F. P. de Gracia (2019). Oil and asset classes implied volatilities: Dynamic connectedness and investment strategies. Working paper.

Antonakakis, N., C. Floros, and R. Kizys (2016). Dynamic spillover effects in futures markets: Uk and us evidence. International Review of Financial Analysis 48, 406-418.

Antonakakis, N. and D. Gabauer (2017). Refined measures of dynamic connectedness based on tvp-var.

Antonakakis, N., D. Gabauer, R. Gupta, and V. Plakandaras (2018). Dynamic connectedness of uncertainty across developed economies: A time-varying approach. Economics Letters 166, 63-75.

Antonakakis, N. and R. Kizys (2015). Dynamic spillovers between commodity and currency markets. International Review of Financial Analysis 41, 303-319.

Bae, K.-H., G. Karolyi, and R. Stulz (2003). A new approach to measuring financial contagion. Review of Financial Studies 16(3), 717-763.

Baele, L. (2005). Volatility spillover effects in european equity markets. Journal of Financial and Quantitative Analysis 40(2), 373-401. 
Baillie, R. and T. Bollerslev (1991). Intra-day and inter-market volatility in foreign exchange rates. Review of Economic Studies 58(3), 565-585.

Balli, F., H. Hajhoj, S. Basher, and H. Ghassan (2015). An analysis of returns and volatility spillovers and their determinants in emerging asian and middle eastern countries. International Review of Economics and Finance 39, $311-325$.

Baur, D. G. and B. M. Lucey (2010). Is gold a hedge or a safe haven? an analysis of stocks, bonds and gold. Financial Review 45(2), 217-229.

Bekiros, S. (2014). Contagion, decoupling and the spillover effects of the us financial crisis: Evidence from the bric markets. International Review of Financial Analysis 33, 58-69.

Bhar, R., S. Hammoudeh, and M. Thompson (2008). Component structure for nonstationary time series: Application to benchmark oil prices. International Review of Financial Analysis 17(5), 971-983.

Bhuyan, R., M. Robbani, B. Talukdar, and A. Jain (2016). Information transmission and dynamics of stock price movements: An empirical analysis of brics and us stock markets. International Review of Economics and Finance 46, 180-195.

Bialkowski, J., M. Bohl, and D. Serwa (2006). Testing for financial spillovers in calm and turbulent periods. Quarterly Review of Economics and Finance 46(3), 397-412.

Bouri, E., M. de Boyrie, and I. Pavlova (2017). Volatility transmission from commodity markets to sovereign cds spreads in emerging and frontier countries. International Review of Financial Analysis 49, 155-165.

Corbet, S., C. Gurdgiev, and A. Meegan (2018). Long-term stock market volatility and the influence of terrorist attacks in europe. Quarterly Review of Economics and Finance 68, 118-131.

Corbet, S., Y. Hou, Y. Hu, B. M. Lucey, and L. Oxley (2020). Aye corona! the contagion effects of being named corona during the covid-19 pandemic. Finance Research Letters, 101591.

Corbet, S., Y. Hou, Y. Hu, and L. Oxley (2020). The influence of the covid-19 pandemic on asset-price discovery: Testing the case of chinese informational asymmetry. Available at SSRN.

Corbet, S., C. Larkin, B. Lucey, A. Meegan, and L. Yarovaya (2020). Cryptocurrency reaction to fomc announcements: Evidence of heterogeneity based on blockchain stack position. Journal of Financial Stability 46.

Corbet, S., C. J. Larkin, and B. M. Lucey (2020). The contagion effects of the covid-19 pandemic: Evidence from gold and cryptocurrencies. Finance Research Letters, Forthcoming, Available at: http://dx.doi.org/10.2139/ssrn.3564443.

Corbet, S., B. Lucey, M. Peat, and S. Vigne (2018). Bitcoin futures-what use are they? Economics Letters 172, 23-27.

Corbet, S., B. M. Lucey, and L. Yarovaya (2019). The financial market effects of cryptocurrency energy usage. Available at SSRN 3412194.

Corbet, S., A. Meegan, C. Larkin, B. Lucey, and L. Yarovaya (2018). Exploring the dynamic relationships between cryptocurrencies and other financial assets. Economics Letters 165, 28-34.

Corbet, S., J. O'Connell, M. Efthymiou, C. Guiomard, and B. Lucey (2019). The impact of terrorism on european tourism. Annals of Tourism Research 75, 1-17.

Corsetti, G., M. Pericoli, and M. Sbracia (2005). 'some contagion, some interdependence': More pitfalls in tests of financial contagion. Journal of International Money and Finance 24(8), 1177-1199. 
Cotter, J. and K. Dowd (2010). Intra-day seasonality in foreign exchange market transactions. International Review of Economics and Finance 19(2), 287-294.

Diebold, F. and K. Yilmaz (2009). Measuring financial asset return and volatility spillovers, with application to global equity markets. Economic Journal 119(534), 158-171.

Diebold, F. X. and K. Yilmaz (2012). Better to give than to receive: Predictive directional measurement of volatility spillovers. International Journal of Forecasting 28(1), 57-66.

Do, H., R. Brooks, S. Treepongkaruna, and E. Wu (2016). Stock and currency market linkages: New evidence from realized spillovers in higher moments. International Review of Economics and Finance 42, 167-185.

Du, X., C. Yu, and D. Hayes (2011). Speculation and volatility spillover in the crude oil and agricultural commodity markets: A bayesian analysis. Energy Economics 33(3), 497-503.

Engle, R. (2002). Dynamic conditional correlation: A simple class of multivariate generalized autoregressive conditional heteroskedasticity models. Journal of Business \& Economic Statistics 20(3), 339-350.

Erdogan, O., K. Tata, B. Karahasan, and M. Sengoz (2013). Dynamics of the co-movement between stock and maritime markets. International Review of Economics and Finance 25, 282-290.

Fatai, K., L. Oxley, and F. Scrimgeour (2004). Modelling the causal relationship between energy consumption and gdp in new zealand, australia, india, indonesia, the philippines and thailand. Mathematics and Computers in Simulation 64(3-4), 431-445.

Fernandez-Rodriguez, F., M. Gomez-Puig, and S. Sosvilla-Rivero (2015). Volatility spillovers in emu sovereign bond markets. International Review of Economics and Finance 39, 337-352.

Gabauer, D. and R. Gupta (2018). On the transmission mechanism of country-specific and international economic uncertainty spillovers: Evidence from a tvp-var connectedness decomposition approach. Economics Letters 171, 63-71.

Gamba-Santamaria, S., J. E. Gomez-Gonzalez, J. L. Hurtado-Guarin, and L. F. Melo-Velandia (2017). Stock market volatility spillovers: Evidence for latin america. Finance Research Letters 20, 207-216.

Gannon, G. (2005). Simultaneous volatility transmissions and spillover effects: U.s. and hong kong stock and futures markets. International Review of Financial Analysis 14 (3), 326-336.

Greasley, D. and L. Oxley (1999). International evidence on shock persistence: structural change, nonlinearities and subsample robustness. Applied Economics 31(4), 499-507.

Guesmi, K., S. Saadi, I. Abid, and Z. Ftiti (2019). Portfolio diversification with virtual currency: Evidence from bitcoin. International Review of Financial Analysis 63, 431-437.

Hameed, A., W. Kang, and S. Viswanathan (2010). Stock market declines and liquidity. Journal of Finance 65(1), $257-293$.

Hammoudeh, S., S. Dibooglu, and E. Aleisa (2004). Relationships among u.s. oil prices and oil industry equity indices. International Review of Economics and Finance 13(4), 427-453.

Hong, Y. (2001). A test for volatility spillover with application to exchange rates. Journal of Econometrics 103(1-2), $183-224$.

Ji, Q., E. Bouri, C. Lau, and D. Roubaud (2019). Dynamic connectedness and integration in cryptocurrency markets. International Review of Financial Analysis 63, 257-272. 
Katsiampa, P., S. Corbet, and B. Lucey (2019a). High frequency volatility co-movements in cryptocurrency markets. Journal of International Financial Markets, Institutions and Money 62, 35-52.

Katsiampa, P., S. Corbet, and B. Lucey (2019b). Volatility spillover effects in leading cryptocurrencies: A bekkmgarch analysis. Finance Research Letters 29, 68-74.

Kim, B.-H., H. Kim, and B.-S. Lee (2015). Spillover effects of the u.s. financial crisis on financial markets in emerging asian countries. International Review of Economics and Finance 39, 192-210.

Kim, K. and S. Rhee (1997). Price limit performance: Evidence from the tokyo stock exchange. Journal of Finance 52(2), 885-901.

Koop, G., M. H. Pesaran, and S. M. Potter (1996). Impulse response analysis in nonlinear multivariate models. Journal of econometrics 74(1), 119-147.

Koutmos, G. and G. Booth (1995). Asymmetric volatility transmission in international stock markets. Journal of International Money and Finance 14 (6), 747-762.

Krause, T. and Y. Tse (2013). Volatility and return spillovers in canadian and u.s. industry etfs. International Review of Economics and Finance 25, 244-259.

Kumar, D. (2017). Realized volatility transmission from crude oil to equity sectors: A study with economic significance analysis. International Review of Economics and Finance 49, 149-167.

Lau, M., S. Vigne, S. Wang, and L. Yarovaya (2017). Return spillovers between white precious metal etfs: The role of oil, gold, and global equity. International Review of Financial Analysis 52, 316-332.

Lee, B.-S. and O. Rui (2002). The dynamic relationship between stock returns and trading volume: Domestic and cross-country evidence. Journal of Banking and Finance 26(1), 51-78.

Lin, A. (2006). Has the asian crisis changed the role of foreign investors in emerging equity markets: Taiwan's experience. International Review of Economics and Finance 15(3), 364-382.

Liu, J., R. F. Stambaugh, and Y. Yuan (2019). Size and value in china. Journal of Financial Economics 134(1), $48-69$.

Liu, L. (2014). Extreme downside risk spillover from the united states and japan to asia-pacific stock markets. International Review of Financial Analysis 33, 39-48.

Longstaff, F. (2010). The subprime credit crisis and contagion in financial markets. Journal of Financial Economics 97(3), 436-450.

Ma, H., L. Oxley, and J. Gibson (2009). Substitution possibilities and determinants of energy intensity for china. Energy Policy 37(5), 1793-1804.

Ma, H., L. Oxley, J. Gibson, and B. Kim (2008). China's energy economy: Technical change, factor demand and interfactor/interfuel substitution. Energy Economics 30(5), 2167-2183.

Malik, F. and B. Ewing (2009). Volatility transmission between oil prices and equity sector returns. International Review of Financial Analysis 18(3), 95-100.

Malik, F. and S. Hammoudeh (2007). Shock and volatility transmission in the oil, us and gulf equity markets. International Review of Economics and Finance 16(3), 357-368.

Meegan, A., S. Corbet, and C. Larkin (2018). Financial market spillovers during the quantitative easing programmes of the global financial crisis (2007-2009) and the european debt crisis. Journal of International Financial Markets, Institutions and Money 56, 128-148. 
Mensi, W., S. Hammoudeh, D. Nguyen, and S. Kang (2016). Global financial crisis and spillover effects among the u.s. and brics stock markets. International Review of Economics and Finance 42, 257-276.

$\mathrm{Ng}$, A. (2000). Volatility spillover effects from japan and the us to the pacific-basin. Journal of International Money and Finance 19(2), 207-233.

Oxley, L. (2002). Earthquakes and volcanoes: The international conference on modelling and forecasting financial volatility, perth, australia, 7-9 september 2001. Journal of Economic Surveys 16(2), 227-235.

Patton, A. J. (2006). Modelling asymmetric exchange rate dependence. International economic review 47(2), 527556.

Pesaran, H. H. and Y. Shin (1998). Generalized impulse response analysis in linear multivariate models. Economics letters 58(1), 17-29.

Pesaran, M. and A. Pick (2007). Econometric issues in the analysis of contagion. Journal of Economic Dynamics and Control 31(4), 1245-1277.

Pyun, C., S. Lee, and K. Nam (2000). Volatility and information flows in emerging equity market: A case of the korean stock exchange. International Review of Financial Analysis 9(4), 405-420.

Reinhart, C. M. and K. S. Rogoff (2008). Is the 2007 us sub-prime financial crisis so different? an international historical comparison. American Economic Review 98(2), 339-44.

Sadorsky, P. (2012). Correlations and volatility spillovers between oil prices and the stock prices of clean energy and technology companies. Energy Economics 34(1), 248-255.

Shahzad, S., R. Ferrer, L. Ballester, and Z. Umar (2017). Risk transmission between islamic and conventional stock markets: A return and volatility spillover analysis. International Review of Financial Analysis 52, 9-26.

Singh, P., B. Kumar, and A. Pandey (2010). Price and volatility spillovers across north american, european and asian stock markets. International Review of Financial Analysis 19(1), 55-64.

Sklar, A. (1973). Random variables, joint distribution functions, and copulas. Kybernetika 9(6), 449-460.

Smimou, K. and W. Khallouli (2016). On the intensity of liquidity spillovers in the eurozone. International Review of Financial Analysis 48, 388-405.

Susmel, R. and R. Engle (1994). Hourly volatility spillovers between international equity markets. Journal of International Money and Finance 13(1), 3-25.

Syllignakis, M. and G. Kouretas (2011). Dynamic correlation analysis of financial contagion: Evidence from the central and eastern european markets. International Review of Economics and Finance 20(4), 717-732.

Syriopoulos, T., B. Makram, and A. Boubaker (2015). Stock market volatility spillovers and portfolio hedging: Brics and the financial crisis. International Review of Financial Analysis 39, 7-18.

Tsai, I.-C. (2014). Spillover of fear: Evidence from the stock markets of five developed countries. International Review of Financial Analysis 33, 281-288.

Tse, Y. (1999). Price discovery and volatility spillovers in the djia index and futures markets. Journal of Futures Markets 19(8), 911-930.

Xu, Y., N. Taylor, and W. Lu (2018). Illiquidity and volatility spillover effects in equity markets during and after the global financial crisis: An mem approach. International Review of Financial Analysis 56, 208-220. 
Yarovaya, L., J. Brzeszczyński, and C. Lau (2016). Intra- and inter-regional return and volatility spillovers across emerging and developed markets: Evidence from stock indices and stock index futures. International Review of Financial Analysis 43, 96-114.

Yi, S., Z. Xu, and G.-J. Wang (2018). Volatility connectedness in the cryptocurrency market: Is bitcoin a dominant cryptocurrency? International Review of Financial Analysis 60, 98-114.

Zhao, X., C. Scarrott, L. Oxley, and M. Reale (2010). Extreme value modelling for forecasting market crisis impacts. Applied Financial Economics 20(1-2), 63-72. 
Table 1: Descriptive statistics of the 5-minute logarithmic returns

\begin{tabular}{lccccccccc}
\hline \hline Variable & Mean & Median & Max & Min & Std. Dev. & Skewness & Kurtosis & J.B. \\
\hline Coronavirus & 0.0000 & 0.0001 & 0.0421 & -0.0502 & 0.0041 & -1.3621 & 38.7256 & $0.0000^{* * *}$ & 1,982 \\
Influenza & 0.0000 & 0.0000 & 0.0276 & -0.0507 & 0.0039 & -1.8024 & 35.4192 & $0.0000^{* * *}$ & 1,982 \\
Facemask & 0.0000 & 0.0000 & 0.0635 & -0.0816 & 0.0064 & -0.1691 & 42.9103 & $0.0000^{* * *}$ & 1,982 \\
CSI300 & 0.0000 & 0.0000 & 0.0328 & -0.0478 & 0.0029 & -1.4205 & 62.2964 & $0.0000^{* * *}$ & 1,982 \\
Dollar/RMB & 0.0000 & 0.0000 & 0.0074 & -0.0054 & 0.0005 & 1.4988 & 59.1892 & $0.0000^{* * *}$ & 1,982 \\
Gold & 0.0000 & 0.0000 & 0.0557 & -0.0398 & 0.0029 & 3.1601 & 135.6940 & $0.0000^{* * *}$ & 1,982 \\
Oil & -0.0002 & 0.0000 & 0.0790 & -0.0945 & 0.0068 & -1.4344 & 60.9393 & $0.0000^{* * *}$ & 1,982 \\
Soybean & 0.0001 & 0.0000 & 0.0304 & -0.0695 & 0.0029 & -5.8658 & 188.7182 & $0.0000^{* * *}$ & 1,982 \\
Bitcoin & 0.0000 & 0.0000 & 0.1508 & -0.4709 & 0.0147 & -16.1585 & 557.0716 & $0.0000^{* * *}$ & 1,982 \\
\hline \hline
\end{tabular}

Note: Our sample data runs from 05 February 2020 throughout 12 May 2020, representing 1,982 observations. 
Table 2: Methodological structure developed within this research

\begin{tabular}{|c|c|c|c|c|}
\hline & No. of variables & COVID-19 related indices & Financial markets & Frequency \\
\hline Section 5.1 & 8 & Coronavirus, face mask, & $\begin{array}{l}\text { CSI300, gold, oil, } \\
\text { soybean, Dollar/RMB, Bitcoin }\end{array}$ & 5-minute \\
\hline Section 5.2 & 8 & Influenza, face mask, & $\begin{array}{l}\text { CSI300, gold, oil, } \\
\text { soybean, Dollar/RMB, Bitcoin }\end{array}$ & 5-minute \\
\hline Section 5.3 & 8 & $\begin{array}{l}\text { Pairwise spillover differences be- } \\
\text { tween Section } 5.2 \text { and Section } 5.1\end{array}$ & & \\
\hline \multicolumn{5}{|c|}{ Robustness checks } \\
\hline Section 5.4.1 & 9 & $\begin{array}{l}\text { Coronavirus, influenza, } \\
\text { face mask }\end{array}$ & $\begin{array}{l}\text { CSI300, gold, oil, } \\
\text { soybean, Dollar/RMB, Bitcoin }\end{array}$ & 5-minute \\
\hline Section 5.4 .2 & 9 & Pairwise spillover differences & & \\
\hline
\end{tabular}

Note: Further analysis and methodological variants were estimated by the authors. 
Table 3: Summary statistics of dynamic pairwise directional connectedness estimates between the coronavirus index and financial assets based on an eight-variable model.

\begin{tabular}{lccccc}
\hline \hline Coronavirus relationship with & Mean & Median & Min & Max & Std. Dev. \\
\hline Facemask Index & 0.5628 & 0.5823 & 0.4234 & 0.6157 & 0.0428 \\
CSI 300 & 0.0765 & 0.0772 & -0.0791 & 0.2413 & 0.0452 \\
Gold & 0.3255 & 0.3244 & 0.3167 & 0.3366 & 0.0045 \\
Oil & 0.1857 & 0.1911 & 0.1152 & 0.1999 & 0.0141 \\
Soybean & 0.0412 & 0.0492 & -0.2163 & 0.2424 & 0.0706 \\
US Dollar/RMB & -0.0287 & -0.0218 & -0.1470 & 0.0476 & 0.0418 \\
Bitcoin & 0.1618 & 0.1587 & 0.1070 & 0.2399 & 0.0212 \\
\hline \hline
\end{tabular}

Note: Our sample data runs from 05 February 2020 throughout 12 May 2020, representing 1,982 observations.

Table 4: Summary statistics of dynamic pairwise directional connectedness estimates between the influenza index and financial assets based on an eight-variable model.

\begin{tabular}{lccccc}
\hline \hline Influenza Index relationship with & Mean & Median & Min & Max & Std. Dev. \\
\hline Facemask Index & 0.3036 & 0.3200 & 0.1694 & 0.3552 & 0.0392 \\
CSI 300 & -0.0411 & -0.0361 & -0.1726 & 0.0538 & 0.0461 \\
Gold & 0.1735 & 0.1737 & 0.1610 & 0.1853 & 0.0041 \\
Oil & 0.0609 & 0.0715 & -0.0791 & 0.0816 & 0.0251 \\
Soybean & 0.0354 & 0.0476 & -0.2766 & 0.2002 & 0.0757 \\
US Dollar/RMB & -0.0499 & -0.0400 & -0.1807 & 0.0299 & 0.0438 \\
Bitcoin & 0.0802 & 0.0778 & 0.0382 & 0.1336 & 0.0172 \\
\hline \hline
\end{tabular}

Note: Our sample data runs from 05 February 2020 throughout 12 May 2020, representing 1,982 observations. 
Figure 1: Total number of international COVID-19 cases and recorded deaths

a) Total number of international recorded COVID-19 cases

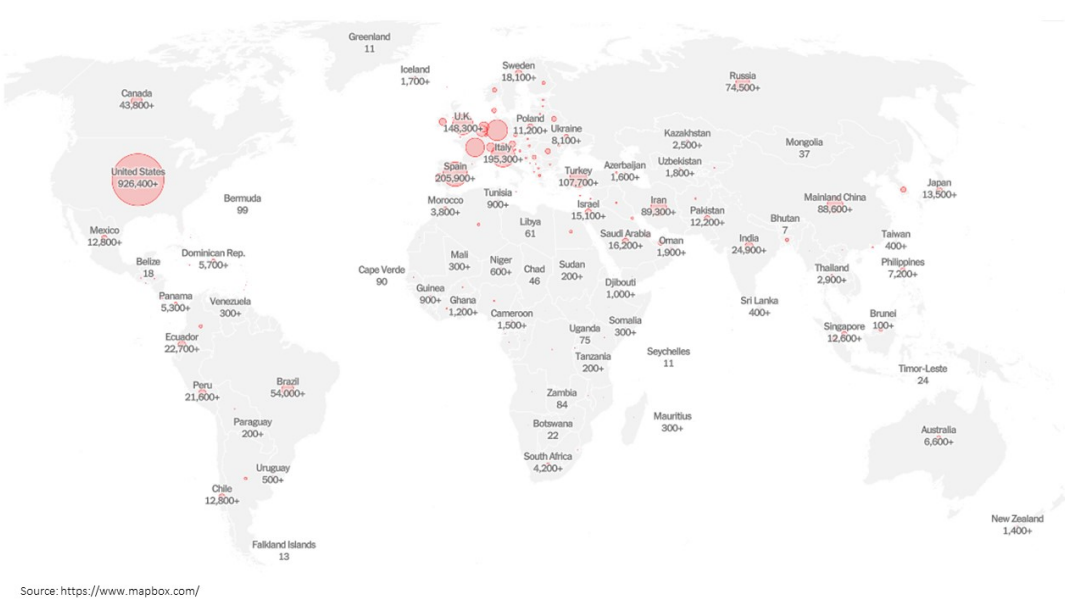

b) Total number of international recorded COVID-19 deaths

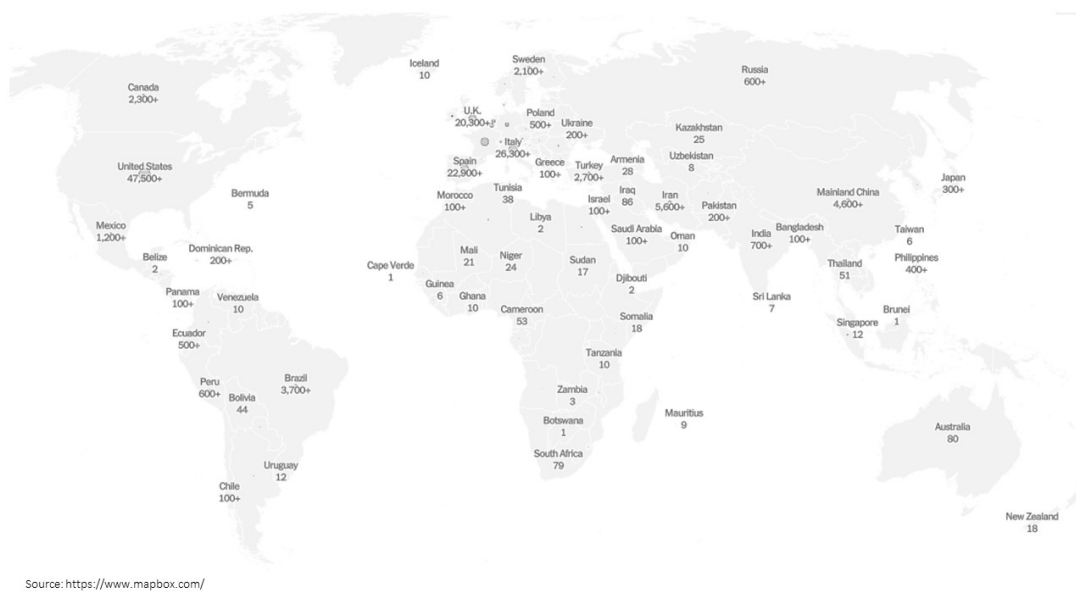

Note: The data was sourced from World Health Organization (WHO). Data correct as of April 2020. 
Figure 2: Cumulative number of confirmed cases and deaths since the beginning of the COVID-19 pandemic

a) Worldwide

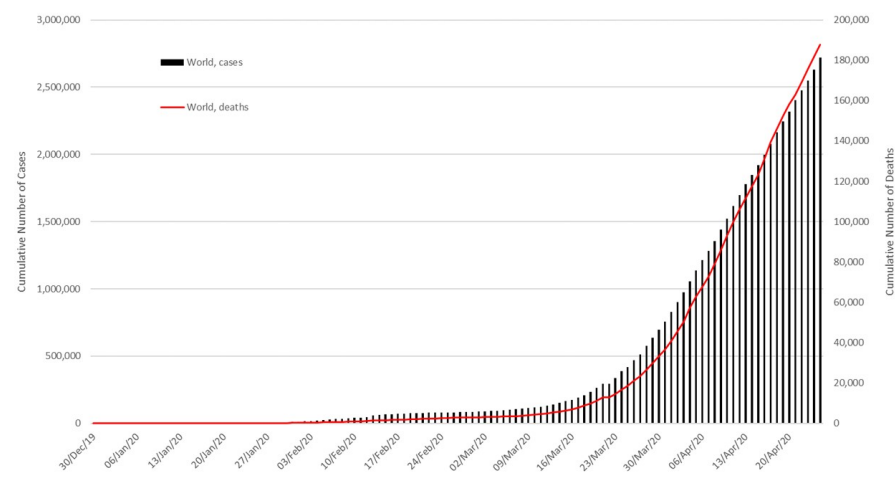

b) China

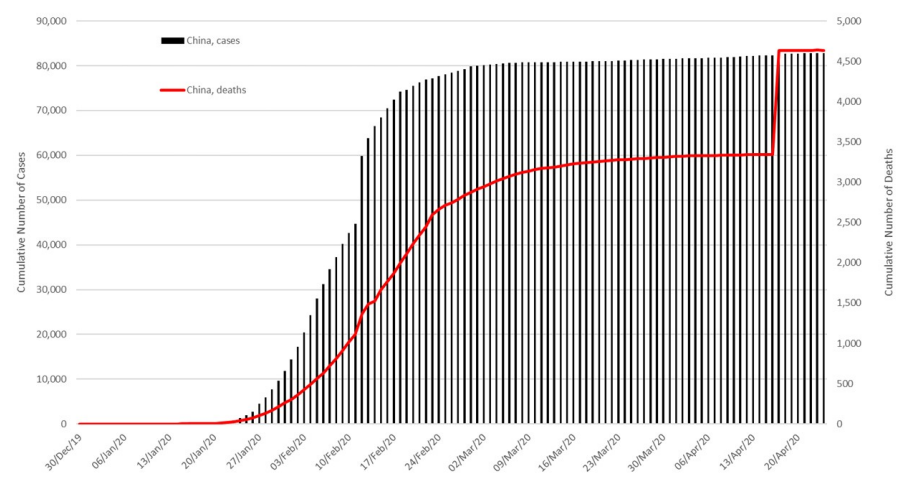

c) United States

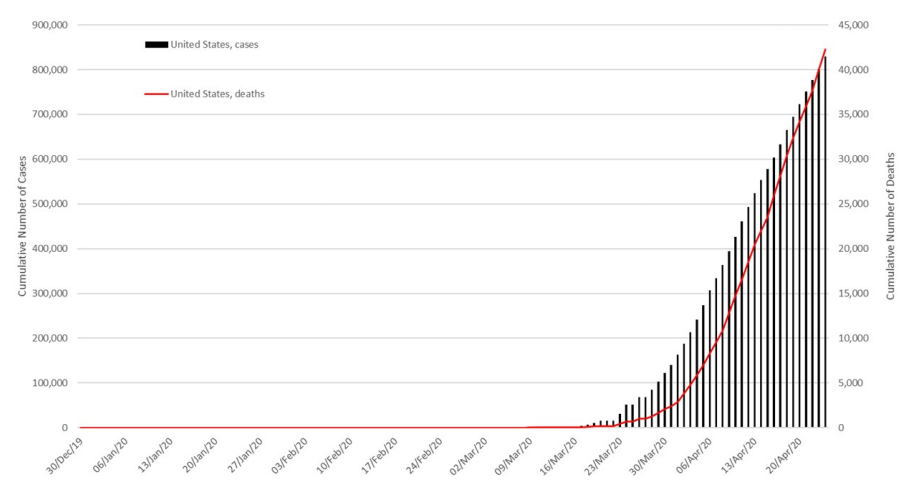

Note: The data was sourced from World Health Organization (WHO) as presented in Corbet et al. [2020]. Data correct as of April 2020. 
Figure 3: Purchasing manufacturers indices (PMI), selected nations, 2017-2020

a) China

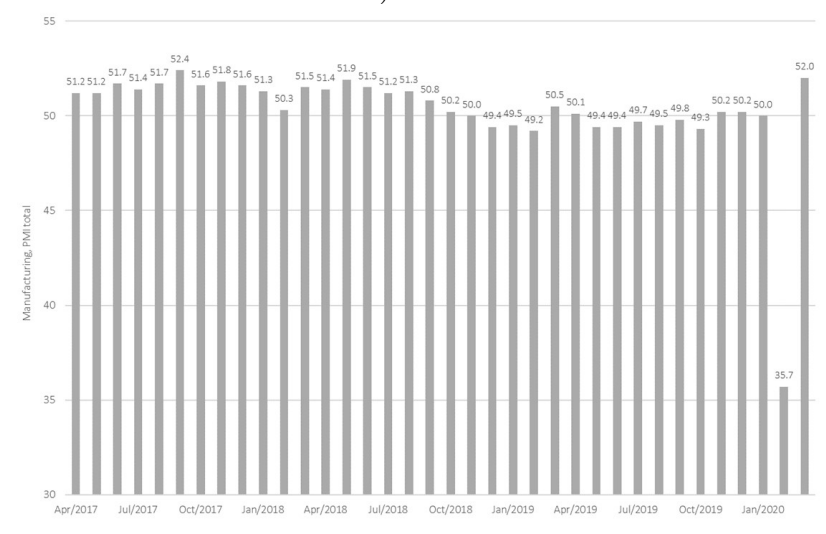

b) United States
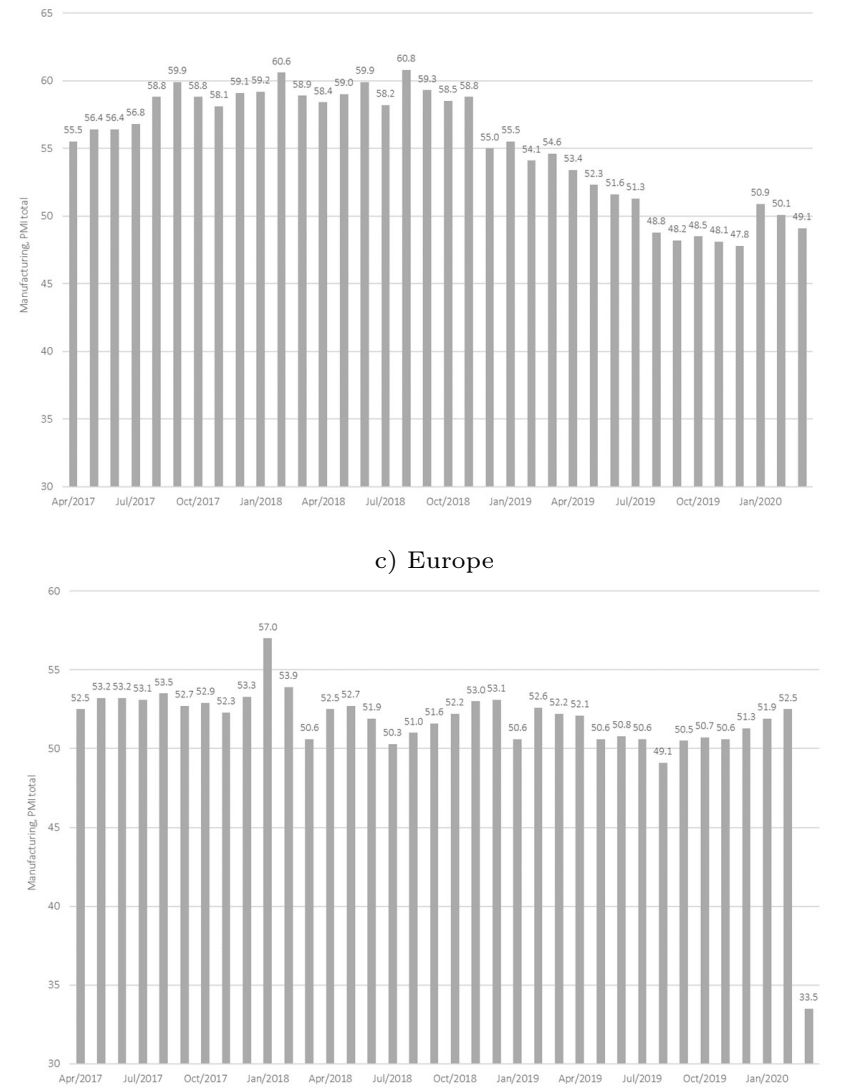

Note: The above data was sourced from IHS Markit. 
Figure 4: Selected stock market performance, 5-minute performance

a) DJIA, United States

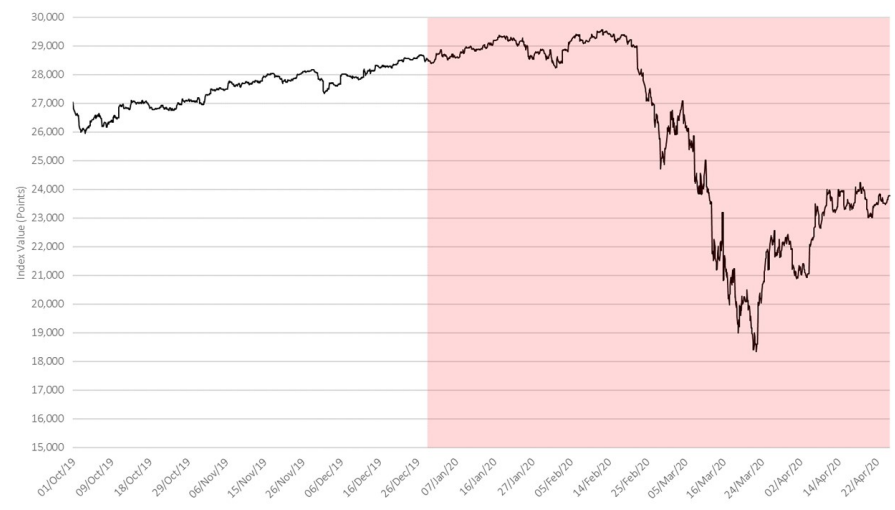

b) DAX, Germany

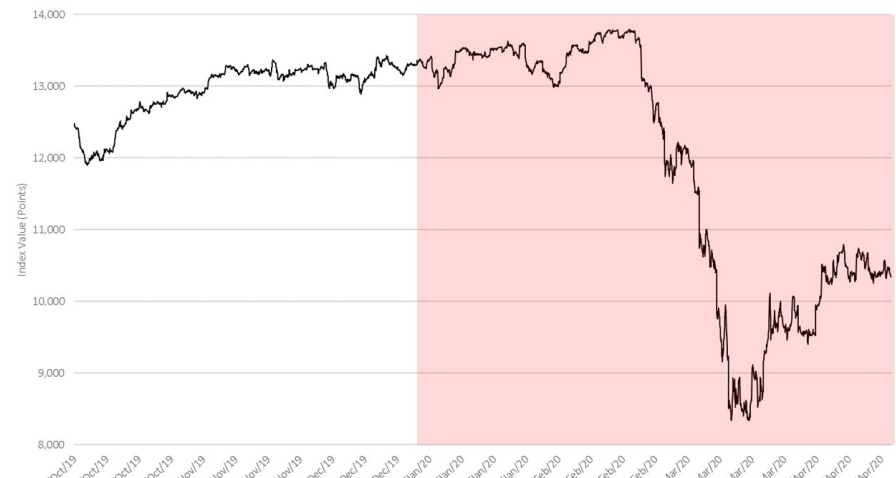

c) Shanghai, China

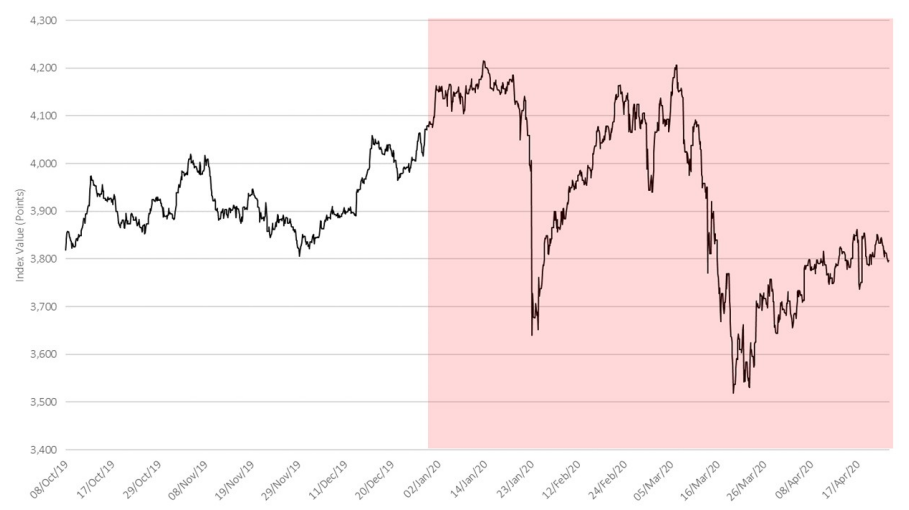

Note: The above data represents the 5-minute price levels of US, German and Chinese markets between the period October 2019 and April 2020. The shaded-area presents the period since 30 December 2019 when the WHO first identified the existence of Coronavirus through a public announcement. 
Figure 5: 5-minute price of West Texas Intermediate Oil, October 2019 through April 2020

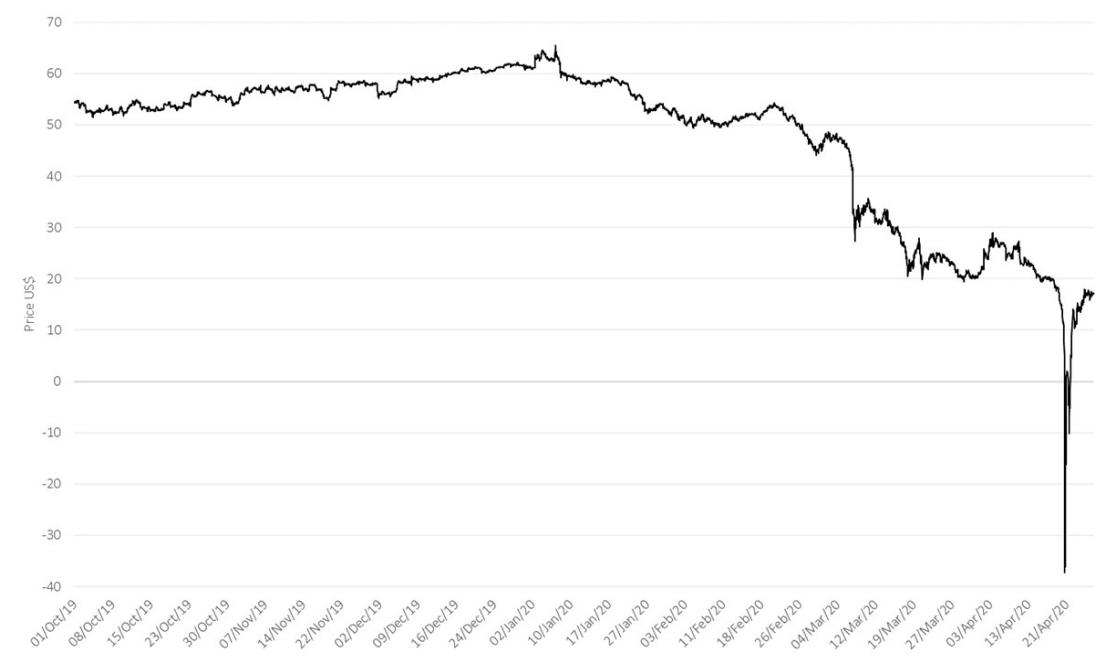

Note: West Texas intermediate (WTI), also known as Texas light sweet, is a grade of crude oil used as a benchmark in oil pricing. This grade is described as light crude oil because of its relatively low density, and sweet because of its low sulphur content. It is the underlying commodity of New York Mercantile Exchange's oil futures contracts. WTI is lighter and sweeter, containing less sulphur, than Brent, and considerably lighter and sweeter than Dubai or Oman. 
Figure 6: Time series plot of 5-minute price data
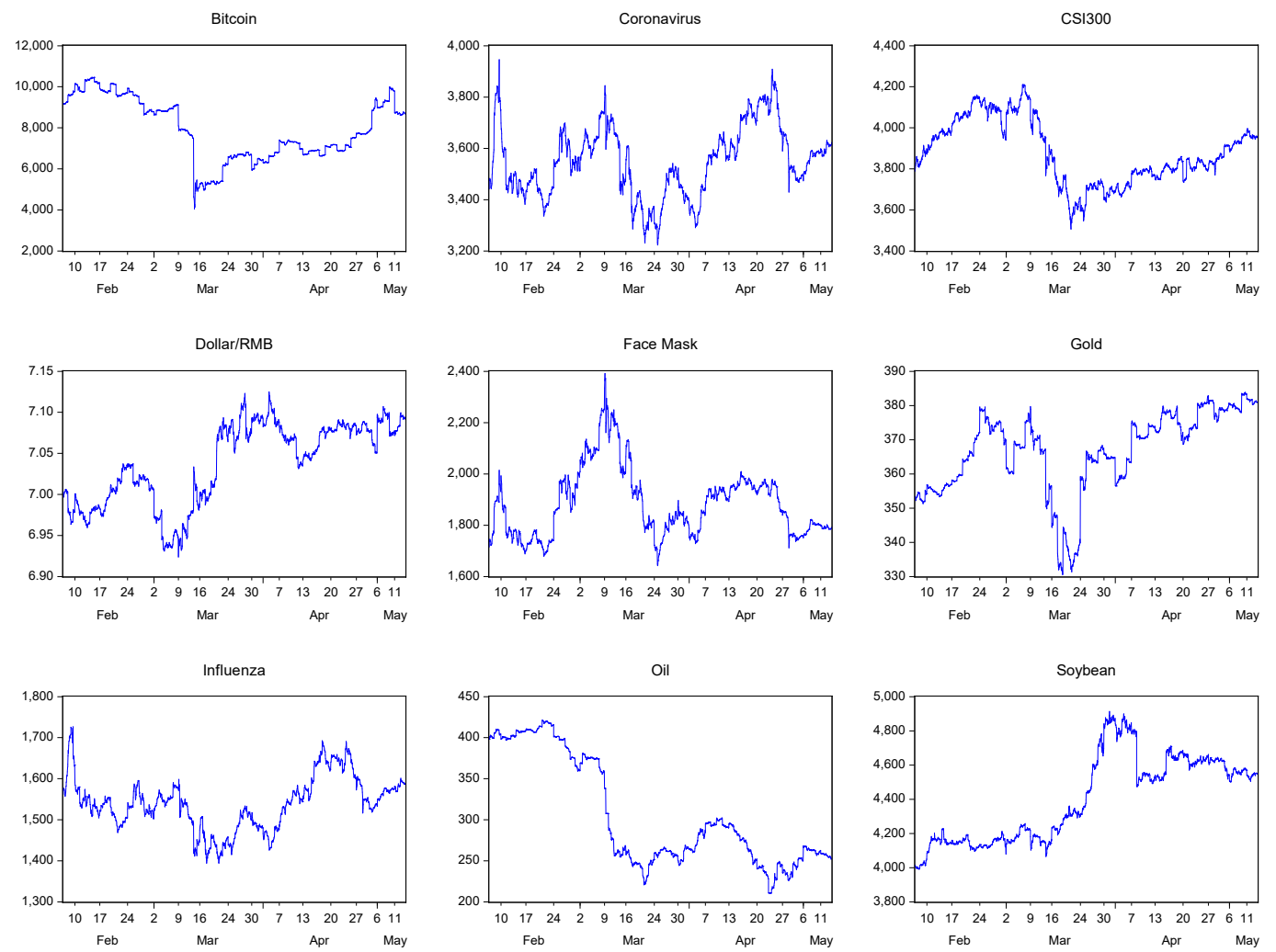

Note: Our sample data runs from 05 February 2020 throughout 12 May 2020, representing 1,982 observations. 
Figure 7: Natural logarithm of 5-minute return series
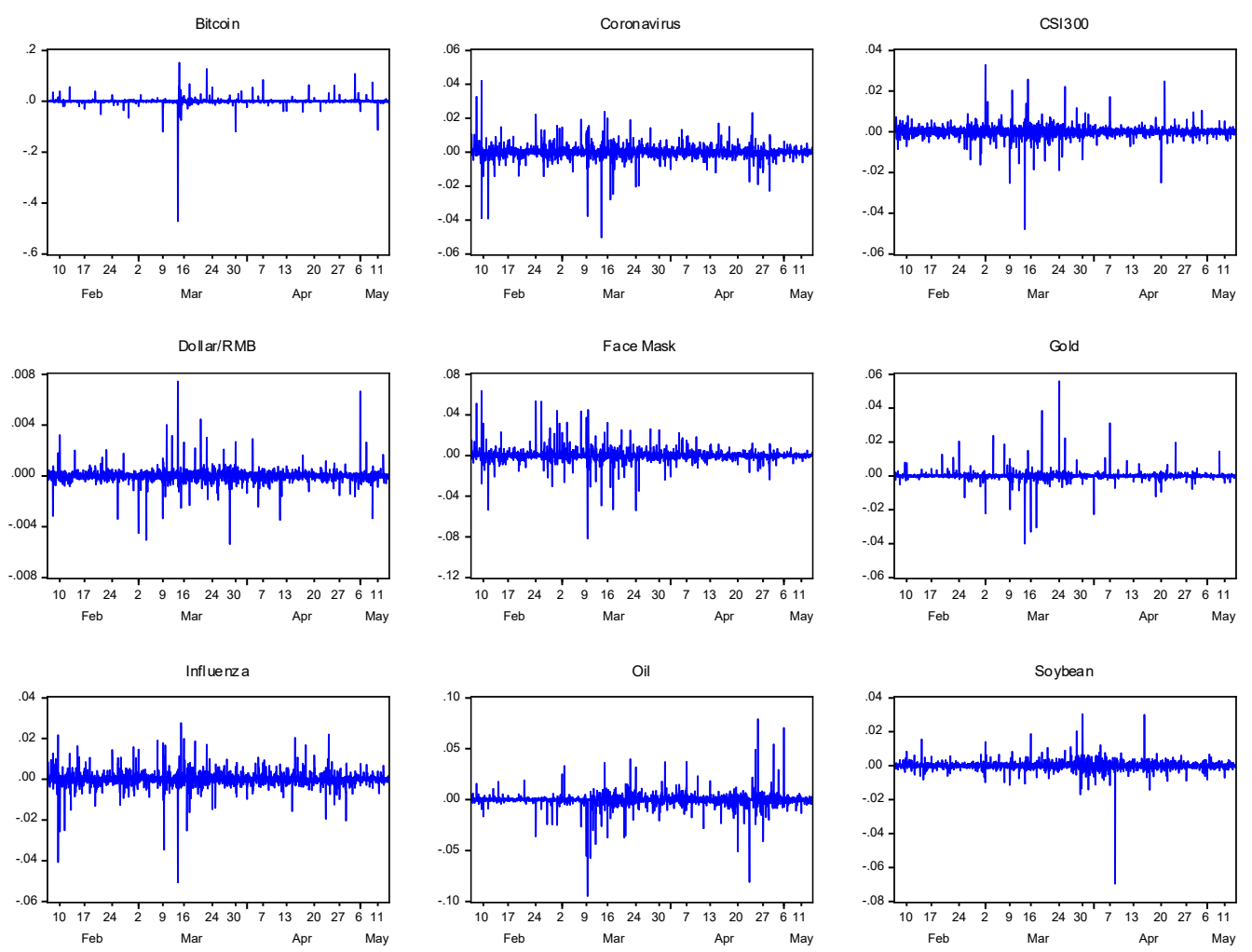

Note: Our sample data runs from 05 February 2020 throughout 12 May 2020, representing 1,982 observations. 
Figure 8: Dynamic total connectedness index based on an eight-variable model.

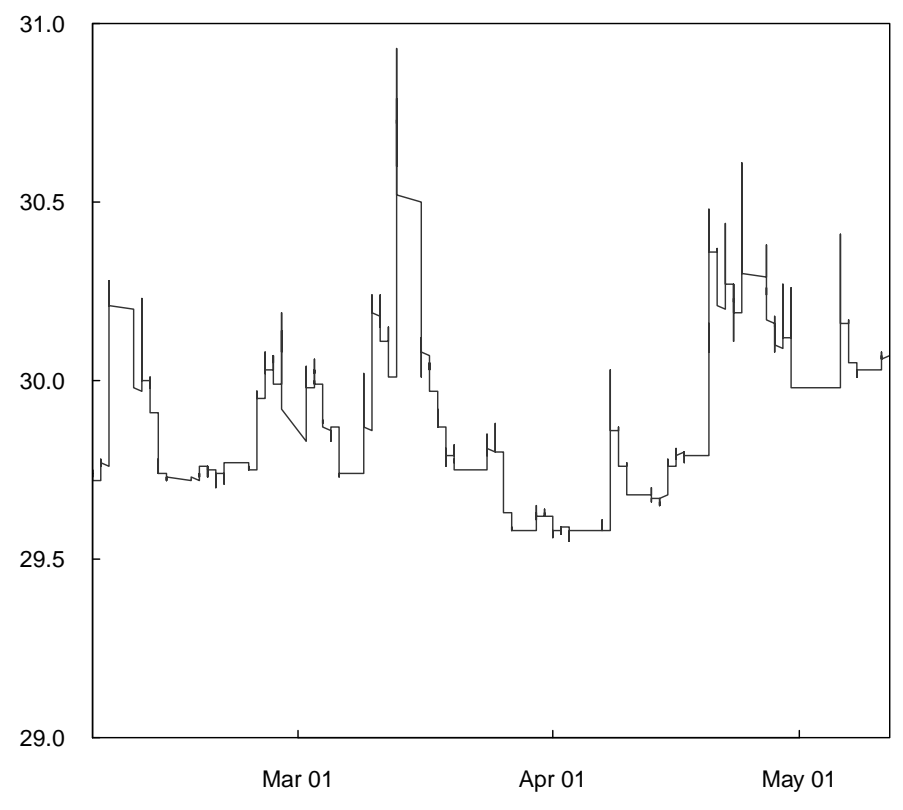

Note: Our sample data runs from 05 February 2020 throughout 12 May 2020, representing 1,982 observations. Further analysis and methodological variants were estimated by the authors. 
Figure 9: Dynamic net directional connectedness for each market based on an eight-variable model.
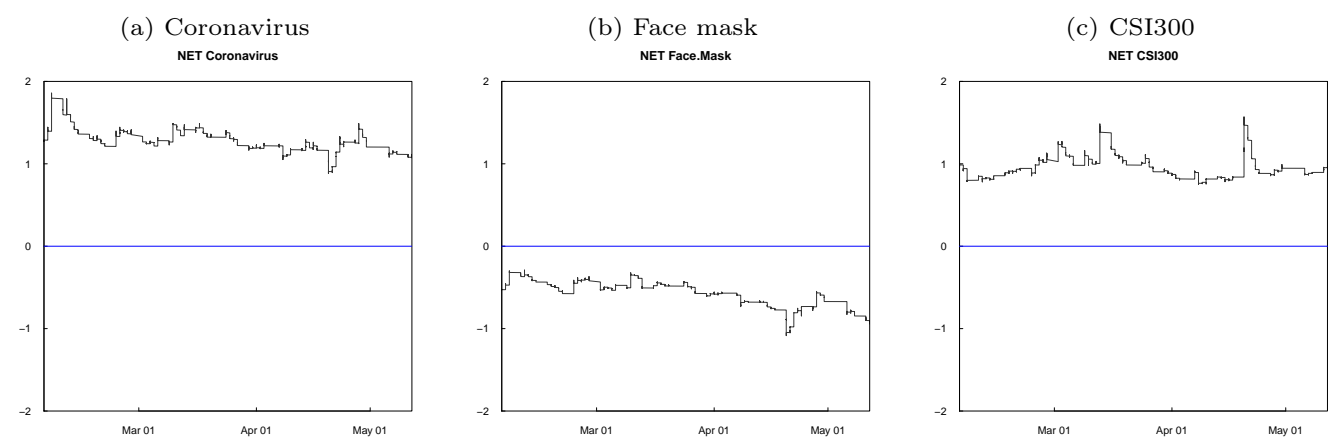

(d) Gold

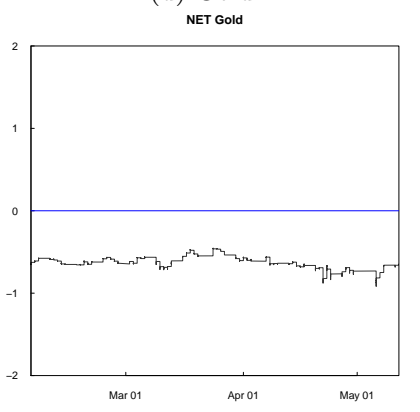

(e) Oil

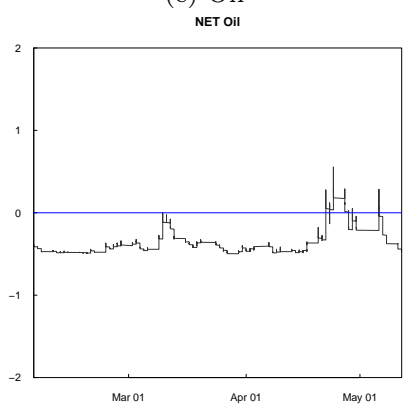

(f) Soybean NET Soybean

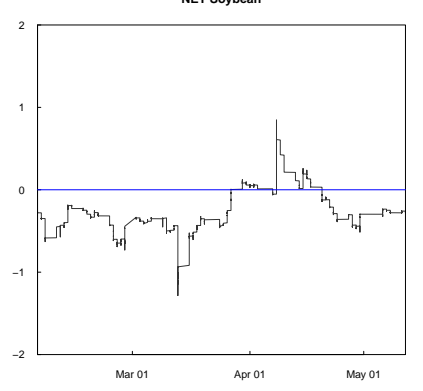

(g) Dollar/RMB

(h) Bitcoin
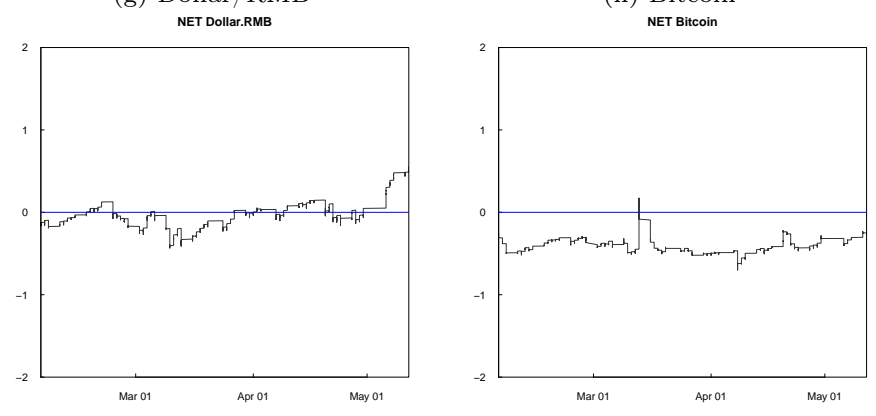

Note: Our sample data runs from 05 February 2020 throughout 12 May 2020, representing 1,982 observations. Further analysis and methodological variants were estimated by the authors. 
Figure 10: Dynamic estimates for pairwise directional connectedness between the coronavirus index and financial assets based on an eight-variable model.

(a) Coronavirus-Facemask Coronavirus-Face.Mask

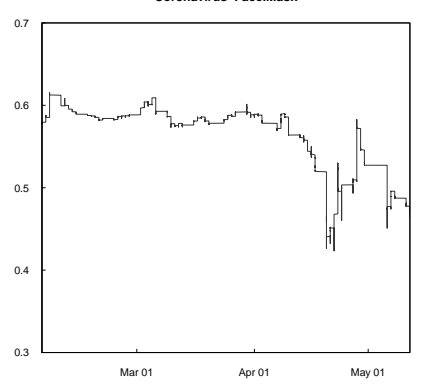

(b) Coronavirus-CSI300
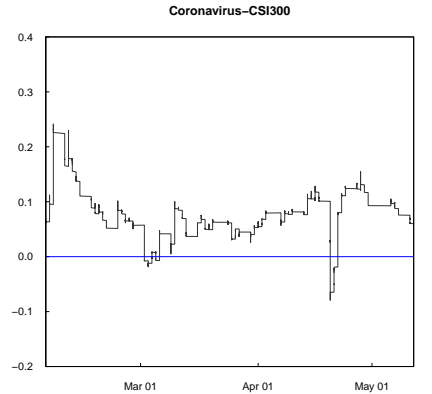

(c) Coronavirus-Gold

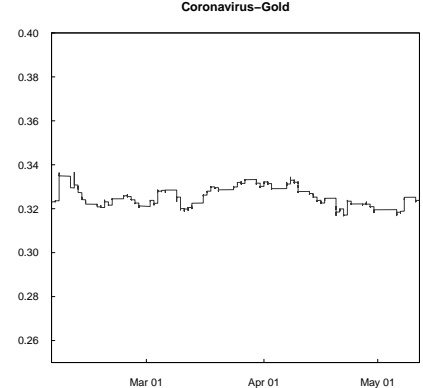

(d) Coronavirus-Oil

coronavirus-oil

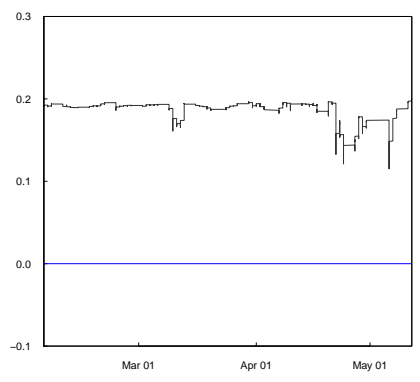

(f) Coronavirus-US Dollar/RMB Coronavirus-Dollar.RMB

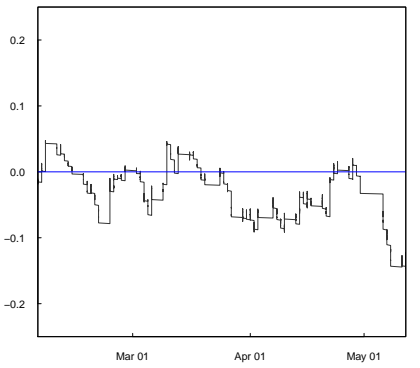

(e) Coronavirus-Soybean

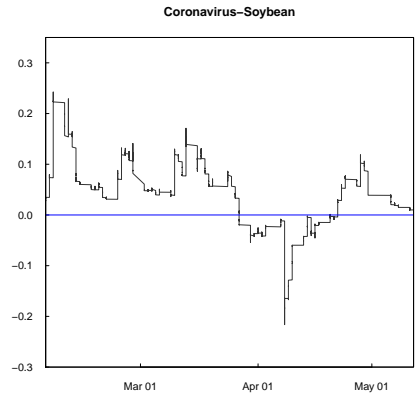

(g) Coronavirus-Bitcoin Coronavirus-Bitcoin

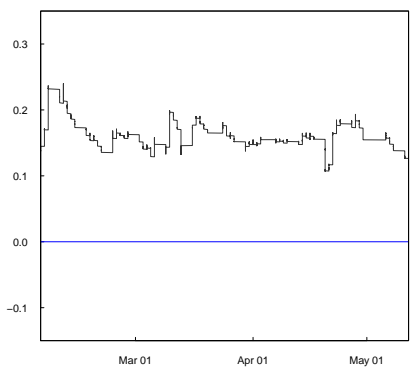

Note: Our sample data runs from 05 February 2020 throughout 12 May 2020, representing 1,982 observations. Further analysis and methodological variants were estimated by the authors. 
Figure 11: Dynamic total connectedness indices of influenza an eight-variable model.

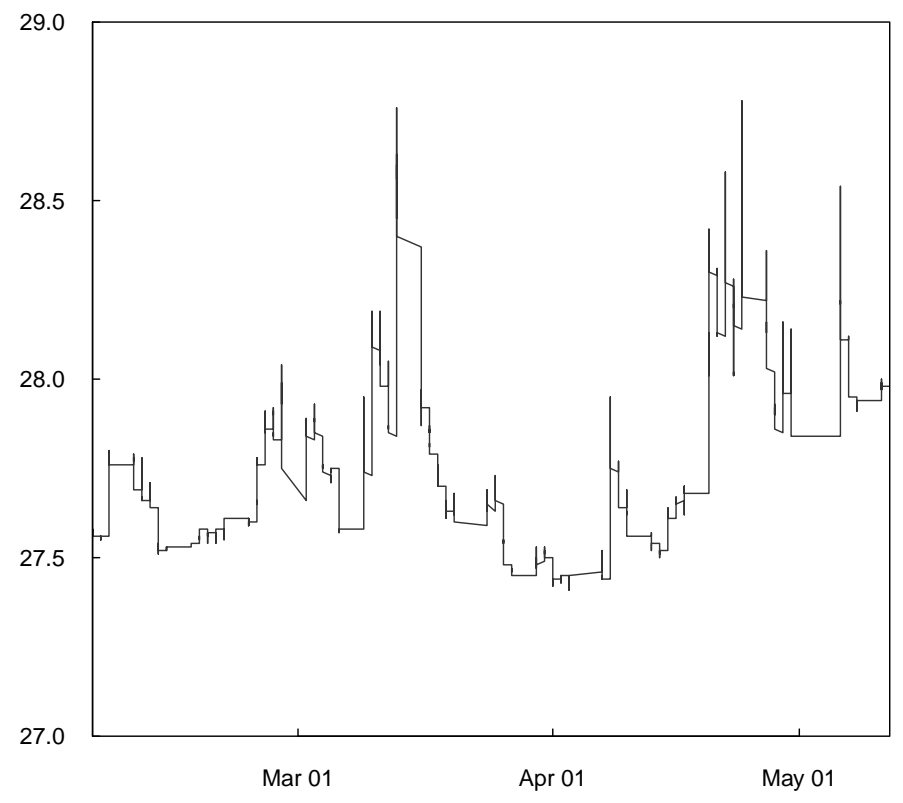

Note: Our sample data runs from 05 February 2020 throughout 12 May 2020, representing 1,982 observations. Further analysis and methodological variants were estimated by the authors. 
Figure 12: Dynamic net directional connectedness for each market based on an eight-variable model.

(a) Influenza

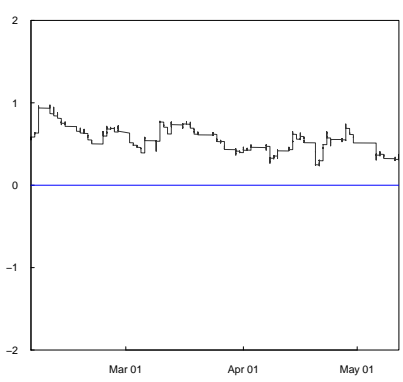

(d) Gold

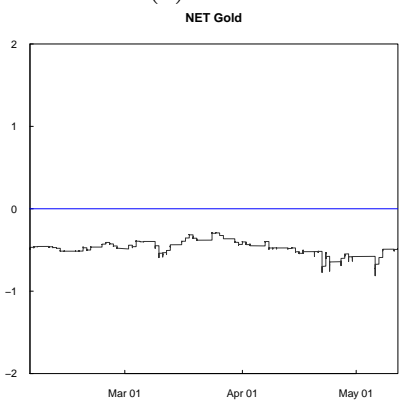

(b) Face mask NET Face.Mask

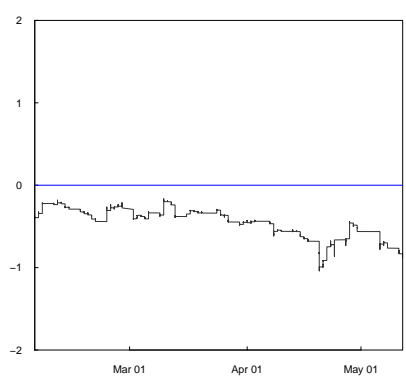

(e) Oil

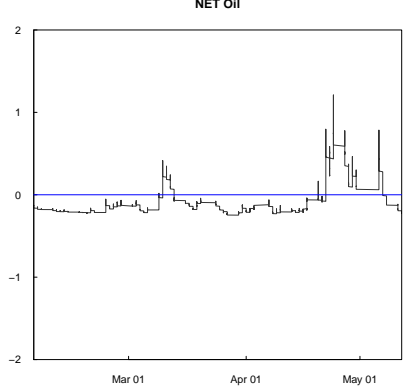

(c) CSI300 NET CSI300

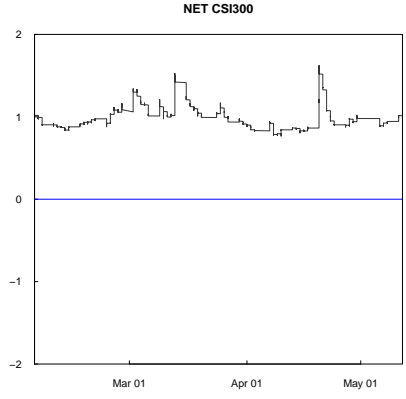

(f) Soybean

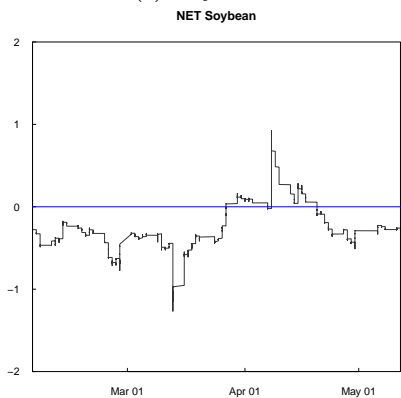

(g) Dollar/RMB

NET Dollar.RMB

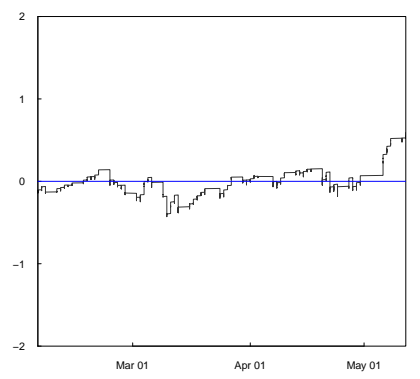

(h) Bitcoin

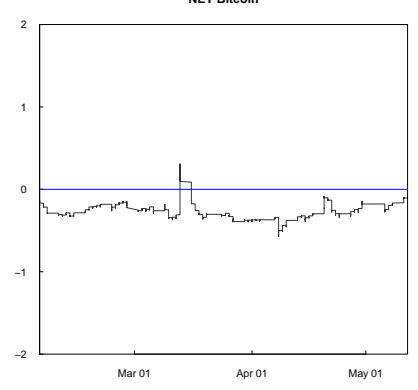

Note: Our sample data runs from 05 February 2020 throughout 12 May 2020, representing 1,982 observations. Further analysis and methodological variants were estimated by the authors. 
Figure 13: Dynamic estimates for pairwise directional connectedness from the influenza index to financial assets based on an eight-variable model.

(a) Influenza-Facemask Influenza-Face.Mask

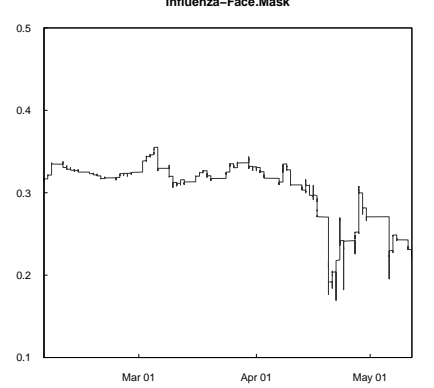

(b) Influenza-CSI300 Influenza-Csi300

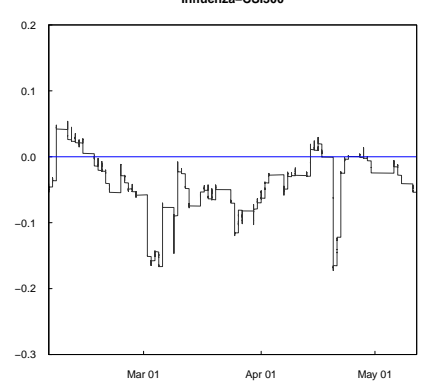

(c) Influenza-Gold

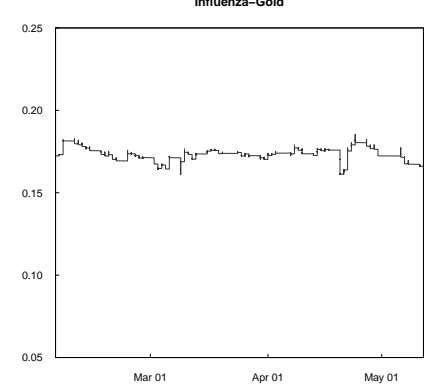

(d) Influenza-Oil

Influenza-oil

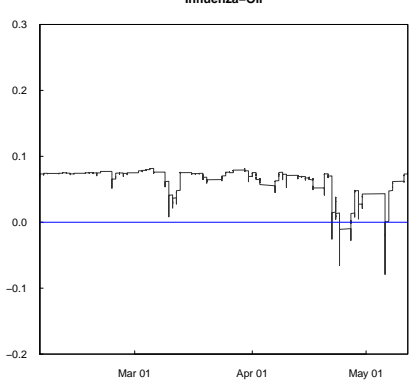

(f) Influenza-US Dollar/RMB Influenza-Dollar.rMB

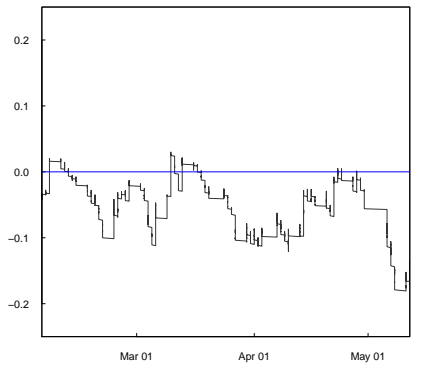

(e) Influenza-Soybean

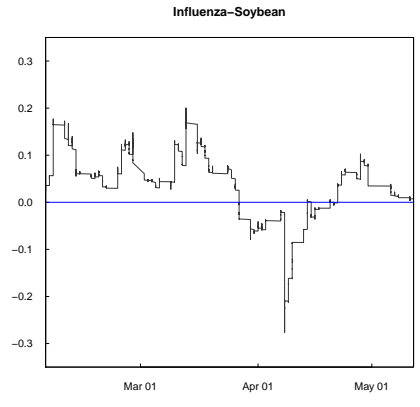

(g) Influenza-Bitcoin Influenza-Bitcoin

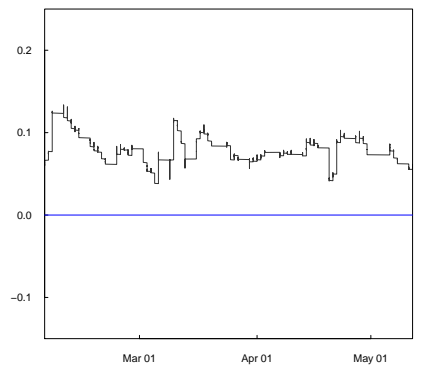

Note: Our sample data runs from 05 February 2020 throughout 12 May 2020, representing 1,982 observations. Further analysis and methodological variants were estimated by the authors. 
Figure 14: Differences in net pairwise directional connectedness from coronavirus and influenza on financial markets based on an eight-variable model.

(a) Facemask

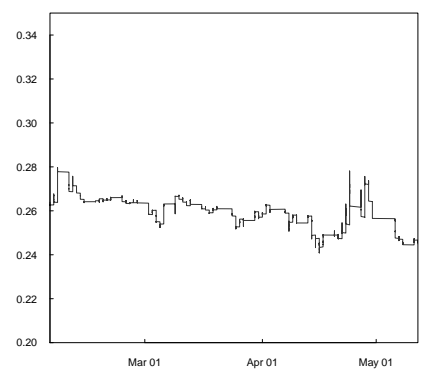

(d) Oil

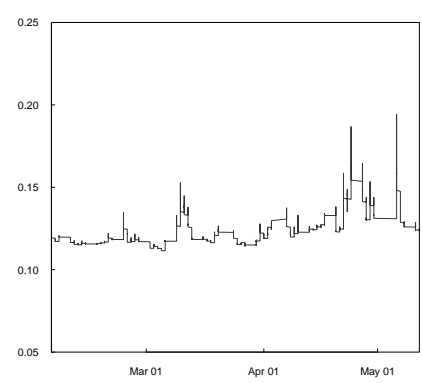

(f) US Dollar/RMB

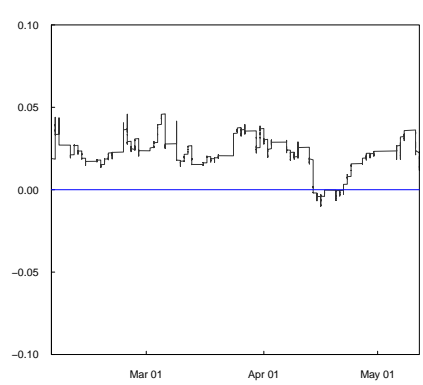

(b) CSI300

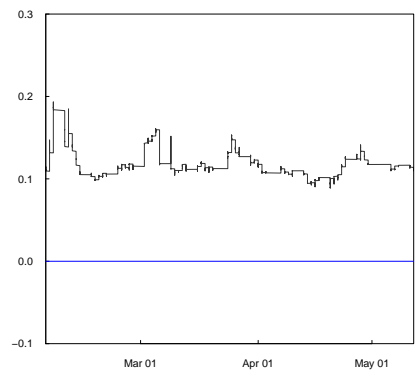

(c) Gold

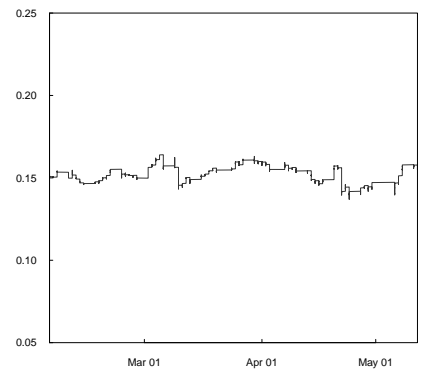

(e) Soybean

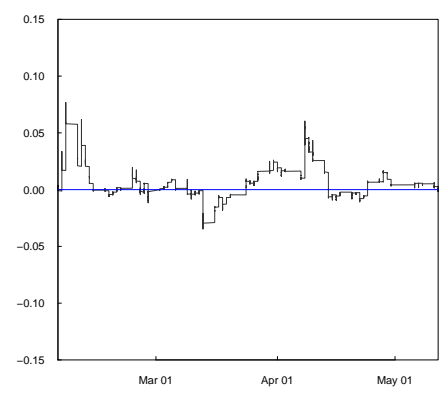

(g) Bitcoin

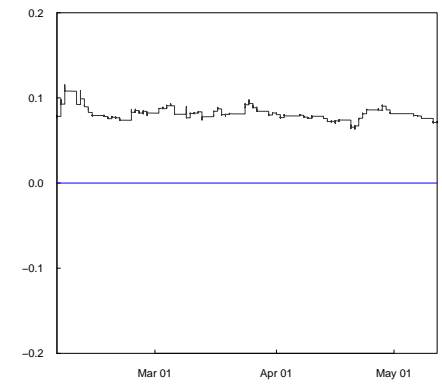

Note: Our sample data runs from 05 February 2020 throughout 12 May 2020, representing 1,982 observations. Further analysis and methodological variants were estimated by the authors. 
Figure 15: Dynamic estimates for net pairwise directional connectedness between the coronavirus index and financial assets based on a nine-variable model.

(a) Coronavirus-Influenza Coronavirus-Intluenza

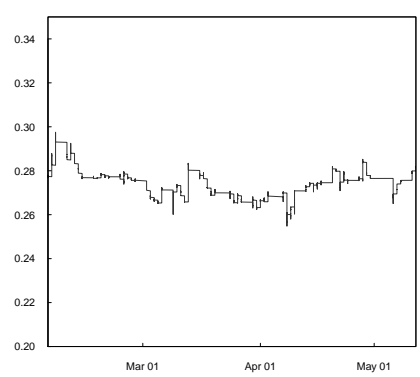

(d) Coronavirus-Gold

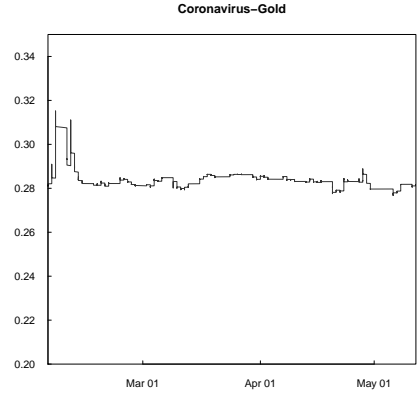

(b) Coronavirus-Facemask Coronavirus-Face.Mask

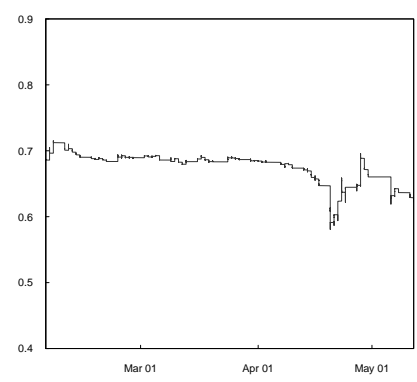

(e) Coronavirus-Oil coronavirus-oil

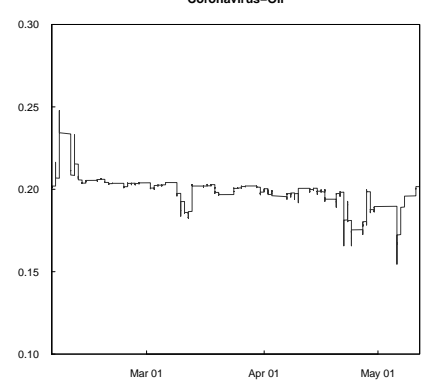

(c) Coronavirus-CSI300 Coronavirus-CS1300

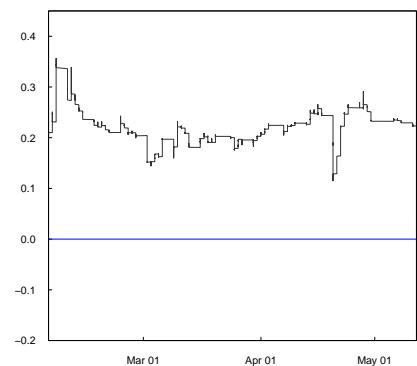

(f) Coronavirus-Soybean coronavirus-Soybean

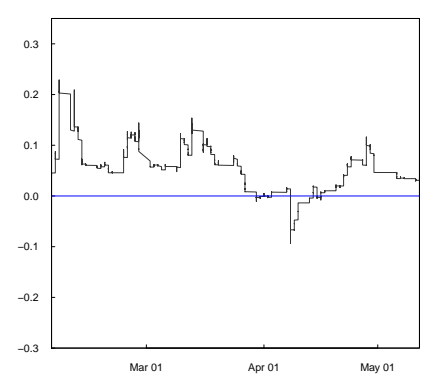

(g) Coronavirus-US Dollar/RMB Coronavirus-Dollar.RMB

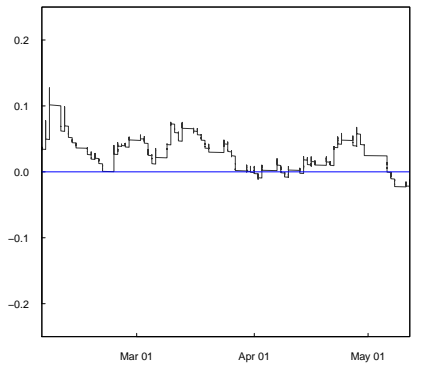

(h) Coronavirus-Bitcoin coronavirus-Bitcoin

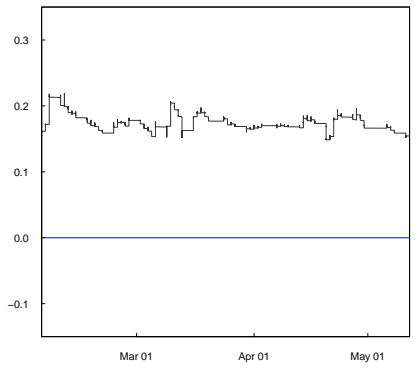

Note: Our sample data runs from 05 February 2020 throughout 12 May 2020, representing 1,982 observations. Further analysis and methodological variants were estimated by the authors. 
Figure 16: Dynamic estimates for net pairwise directional connectedness between the influenza index and financial assets based on a nine-variable model.

(a) Influenza-Facemask Influenza-Face.Mask

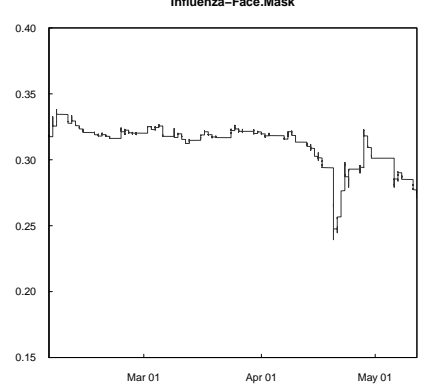

(d) Influenza-Oil

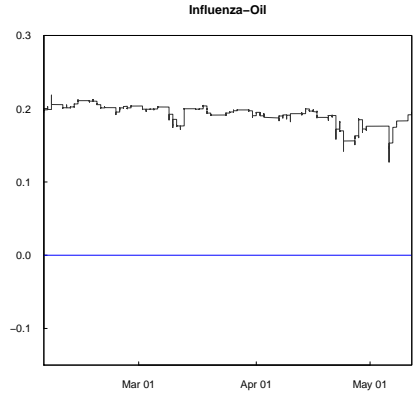

(f) Influenza-US Dollar/RMB Influenza-Dollar.RMB

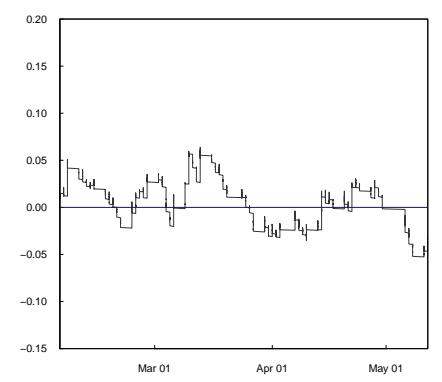

(b) Influenza-CSI300 Influenza-CSI300

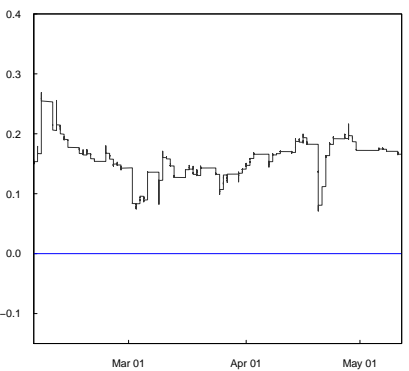

(c) Influenza-Gold Influenza-Gold

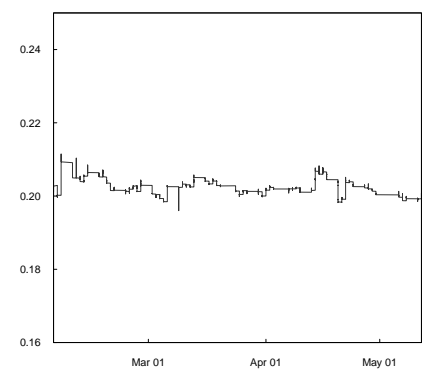

(e) Influenza-Soybean

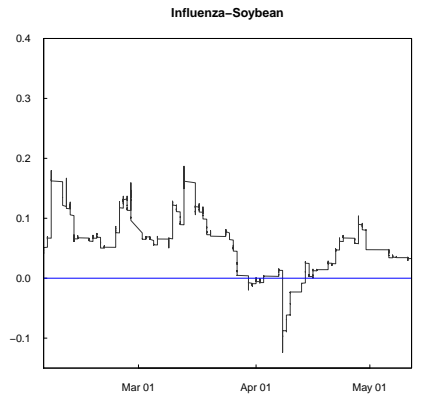

(g) Influenza-Bitcoin Influenza-Bitcoin

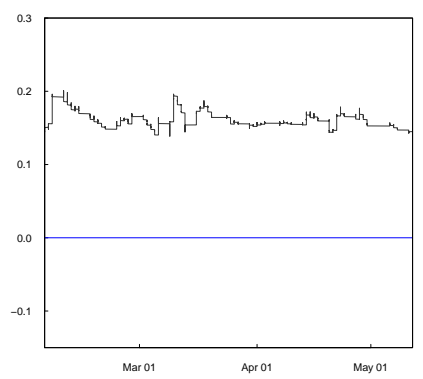

Note: Our sample data runs from 05 February 2020 throughout 12 May 2020, representing 1,982 observations. Further analysis and methodological variants were estimated by the authors. 
Figure 17: Differences in net pairwise directional connectedness from coronavirus and influenza on financial markets based on a nine-variable model.

(a) Facemask

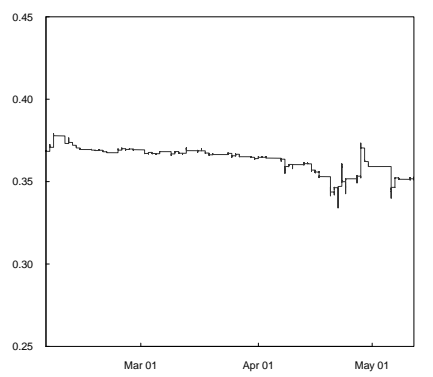

(b) CSI300

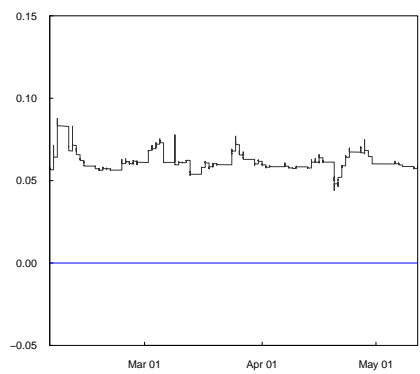

(c) Gold

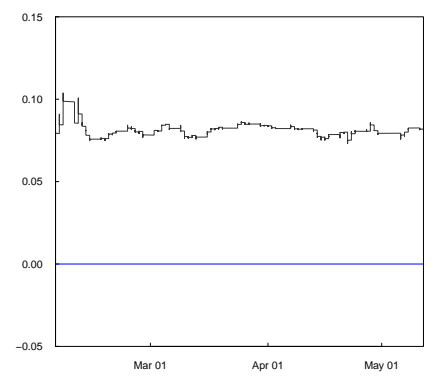

(d) Oil

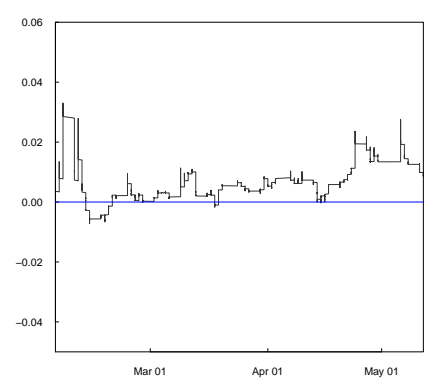

(f) US Dollar/RMB

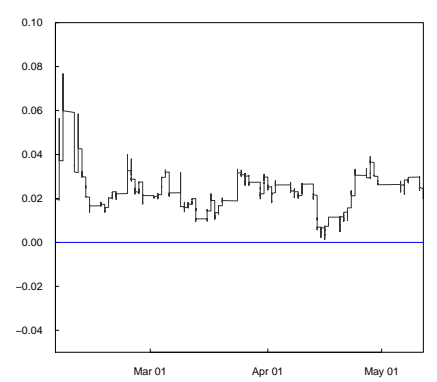

(e) Soybean

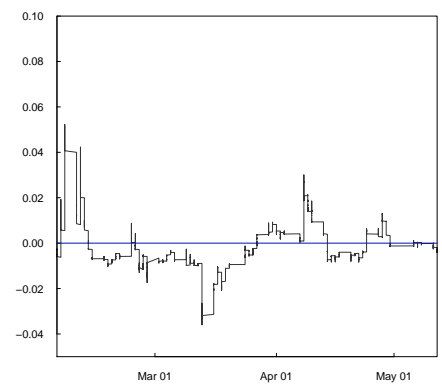

(g) Bitcoin

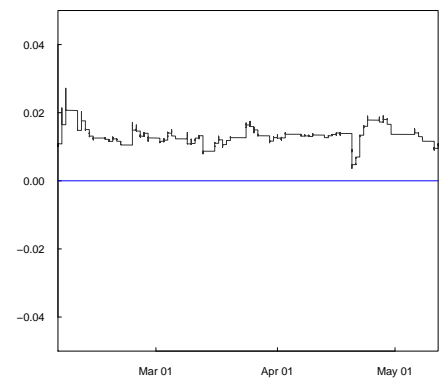

Note: Our sample data runs from 05 February 2020 throughout 12 May 2020, representing 1,982 observations. 